\title{
GENERATION OF STRONG MOTION PULSES DURING HUGE SUBDUCTION EARTHQUAKES AND SCALING OF THEIR GENERATION AREAS
}

\author{
Atsushi NOZU ${ }^{1}$, Masayuki YAMADA ${ }^{2}$, Takashi NAGAO ${ }^{3}$ and Kojiro IRIKURA ${ }^{4}$ \\ ${ }^{1}$ Member of JAEE, Head of Engineering Seismology Division, Port and Airport Research Institute, \\ Yokosuka, Japan, nozu@pari.go.jp \\ ${ }^{2}$ Team Manager, Newjec, Osaka, Japan, yamadams@newjec.co.jp \\ ${ }^{3}$ Professor, Research Center for Urban Safety and Security, Kobe University, Kobe, Japan, \\ nagao@people.kobe-u.ac.jp \\ ${ }^{4}$ Professor, Aichi Institute of Technology, Toyota, Japan, \\ irikura@geor.or.jp
}

\begin{abstract}
Strong ground motions in the frequency range of $0.2-1 \mathrm{~Hz}$ observed along the east coast of Tohoku, Japan, from Miyagi to Ibaraki during the 2011 Tohoku earthquake are characterized by distinct pulses. The generation of such pulses is significantly important especially in the context of seismic design of structures. In this article, examples of strong-motion pulses from huge subduction earthquakes are presented and the relationships between the parameters of the SPGAs (Strong-motion Pulse Generation Areas) and the moment magnitude of the earthquakes are investigated.
\end{abstract}

Key Words: The 2011 Tohoku earthquake, subduction earthquake, strong motion pulse, scaling

\section{INTRODUCTION}

The 2011 Tohoku, Japan, earthquake $\left(M_{\mathrm{w}} 9.0\right)$ is the first M9 earthquake whose strong motions were recorded by the dense strong-motion networks ${ }^{122}$. The occurrence of the earthquake enabled us to analyze actual strong ground motions resulting from an M9 earthquake for the first time in history. In the coming years, there will be increasing opportunity to predict strong ground motions for equally large scenario earthquakes in other regions. When constructing source models for such earthquakes, it is quite important to be guided by the lessons learned from the strong-motion data of the Tohoku earthquake. In particular, if the strong-motion prediction is aimed at providing input ground motions for the design of structures, special attention should be paid to the reliability of the simulation over the frequency range relevant to structural damage.

Regarding port structures, strong ground motions in the frequency range of $0.3-1 \mathrm{~Hz}$ have the largest effects on quay walls ${ }^{3)}$. For buildings, Sakai et al. ${ }^{4)}$ suggested that spectral acceleration in the period range of 1.2-1.5 s, that is, in the frequency range of $0.67-0.83 \mathrm{~Hz}$ is well correlated with damage to wooden houses and low to mid-rise reinforced concrete buildings. In addition, many high-rise buildings have a natural period in the frequency range of $0.2-1 \mathrm{~Hz}$. Thus, the frequency range 
of $0.2-1 \mathrm{~Hz}$ is quite important from an engineering point of view ${ }^{5)}$. Therefore, we focus on the characteristics of strong ground motions over this frequency range in this study, although we notice that some important structures of engineering interest are not covered in the frequency range mentioned above.

The velocity waveforms in the frequency range of $0.2-1 \mathrm{~Hz}$ observed during the 2011 Tohoku earthquake at relatively stiff sites along the coast from Miyagi to Ibaraki Prefectures, relatively close to the causative fault ${ }^{6}$, are characterized by distinct pulses (see 2.). These pulses are important because they appear in the frequency range relevant to structural damage. In this article, the pulses appearing in this frequency range are referred to as "strong-motion pulses".

It is well known that strong-motion pulses generated by shallow crustal earthquakes such as the 1995 Hyogo-ken Nanbu, Japan, earthquake ${ }^{778)}$ and the 1994 Northridge, California, earthquake ${ }^{9)}$ caused significant damage to structures in the near-source region. Therefore, in the current practice of strong-motion prediction for shallow crustal earthquakes, sufficient attention has been paid for the generation of strong-motion pulses. However, the importance of strong-motion pulses for huge subduction earthquakes has not been widely recognized; in the current practice of strong motion prediction for huge subduction earthquakes, the source models have been constructed without paying attention to the generation of strong-motion pulses (see 3.1). As mentioned above, however, strong-motion pulses were actually generated by the Tohoku earthquake, which was a huge subduction earthquake, and they were in the same period range as those generated by shallow crustal earthquakes. Therefore, strong-motion pulses generated by a huge subduction earthquake may cause significant damage to structures when their amplitudes are sufficiently large. Furthermore, as discussed in section 2. , strong-motion pulses are not inherent to the Tohoku earthquake; they were also generated by other huge subduction earthquakes. Thus, it is significantly important to consider the generation of such pulses in the prediction of strong ground motions for huge subduction earthquakes, especially when the prediction is aimed at seismic-resistant design of structures.

In this article, we first present examples of strong-motion pulses from huge subduction earthquakes. Then, we compile source models to reproduce those pulses. Finally, we investigate the characteristics of Strong-motion Pulse Generation Areas (SPGAs), focusing on the relationships between the SPGA parameters and the earthquake size.

\section{EXAMPLES OF STRONG-MOTION PULSES FROM HUGE SUBDUCTION EARTHQUAKES}

In this section, examples of strong-motion pulses from huge subduction earthquakes are cited. We discuss examples from the 2011 Tohoku earthquake are discussed and then we present examples from the 2003 Tokachi-oki, Japan, earthquake $\left(M_{\mathrm{w}} 7.9\right)$, which was the first huge subduction earthquake recorded by the dense strong-motion networks ${ }^{12)}$. Finally, we examine examples from the 1978 Miyagi-ken-oki, Japan, earthquake $\left(M_{\mathrm{w}} 7.6\right)$, which produced important strong-motion records ${ }^{10)}$, although it is not strictly a "huge" subduction earthquake.

\subsection{The 2011 Tohoku earthquake}

The black traces in Fig. 1 show the velocity waveforms in the frequency range of $0.2-1 \mathrm{~Hz}$ observed at five strong-motion stations in Miyagi through Ibaraki Prefectures, namely, MYGH12, Sendai-G, FKS031, FKS011, and IBR007, during the 2011 Tohoku earthquake. Station Sendai-G is a part of the Strong Motion Earthquake Observation in Japanese Ports ${ }^{11}$. Station MYGH12 belongs to the KiK-net ${ }^{2}$, and the surface record rather than borehole record was used. The velocity waveforms in the frequency range of $0.2-1 \mathrm{~Hz}$ at all five stations (Fig.1) are characterized by single or multiple distinctive pulses.

For comparison, examples of strong-motion pulses generated by shallow crustal earthquakes are shown in Fig. 2. The top panel shows the strong-motion pulse observed at Takatori during the 1995 

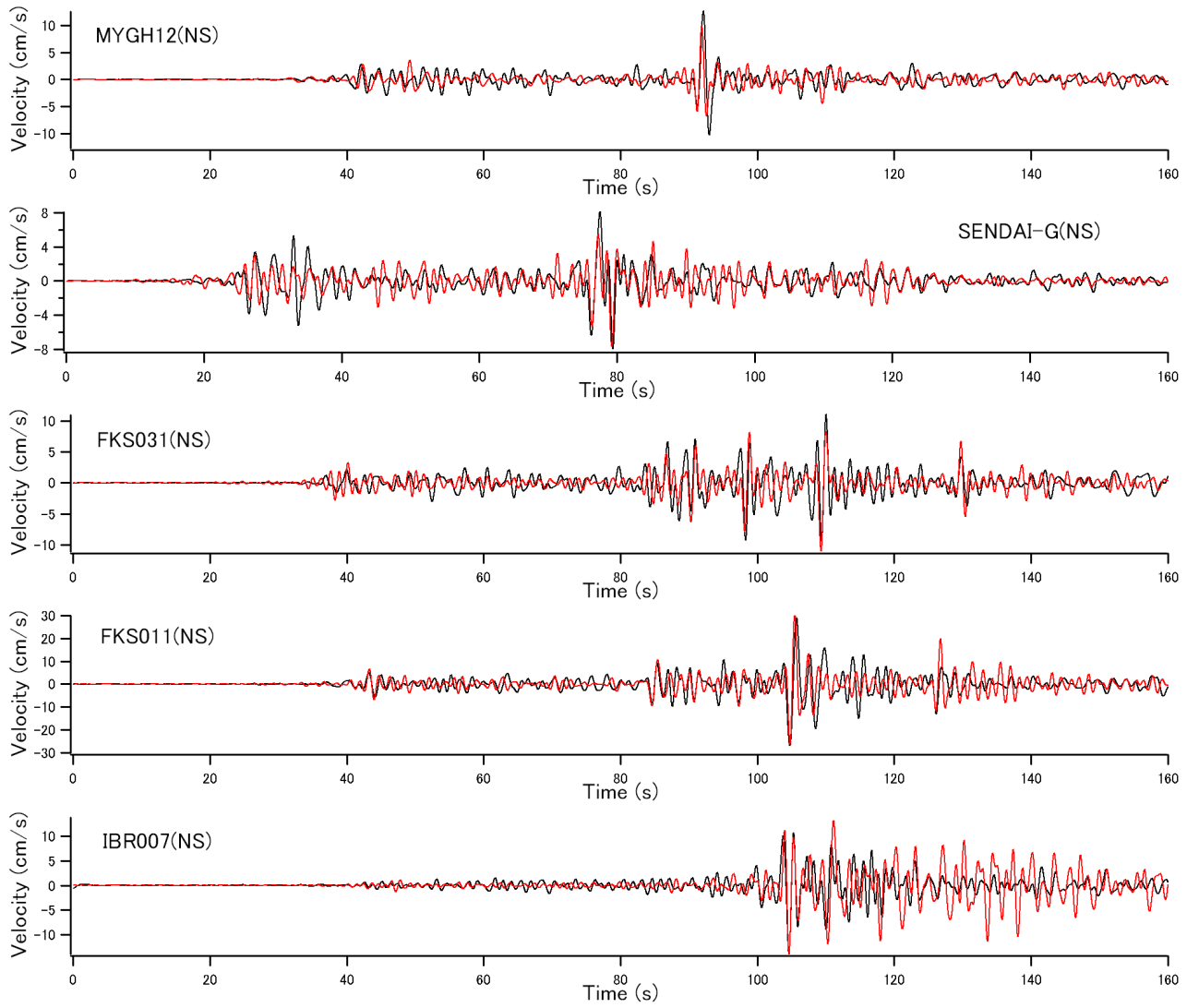

Fig. 1 Examples of strong-motion pulses observed during the 2011 Tohoku earthquake (black lines) and the synthetic waveforms based on the SPGA model (3. ) (red lines). Both are the velocity waveforms in the frequency of $0.2-1 \mathrm{~Hz}$.
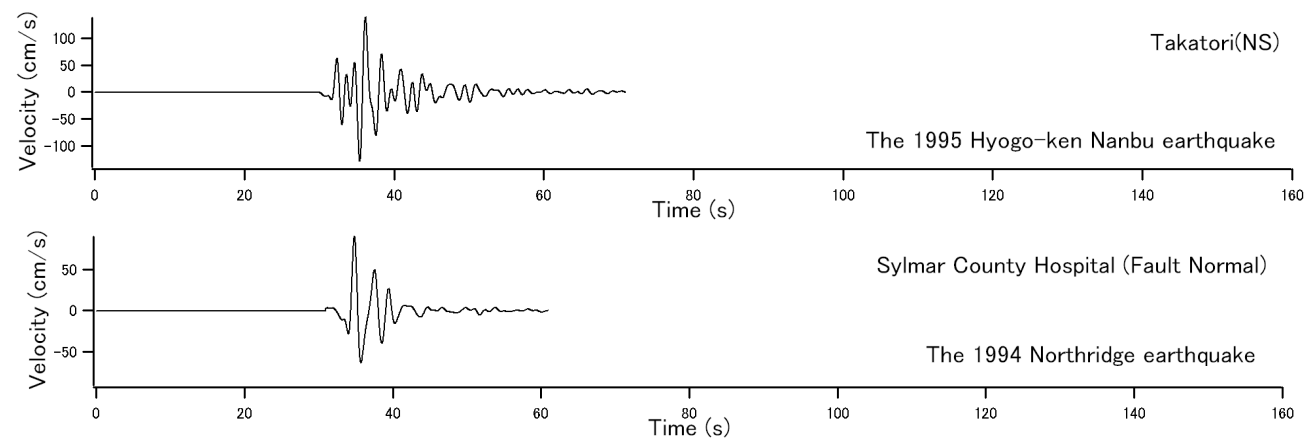

Fig. 2 Examples of strong-motion pulses generated by shallow crustal earthquakes (velocity waveforms in the frequency range of $0.2-1 \mathrm{~Hz}$ ).

Hyogo-ken Nanbu earthquake. The bottom panel shows the strong-motion pulse observed at Sylmar County Hospital during the 1994 Northridge earthquake. Both of these pulses are known to have brought significant damage to structures. Figs. 1 and 2 show that the strong-motion pulses observed during the 2011 Tohoku earthquake are similar to those generated by the shallow crustal earthquakes in terms of the shape and the period.

One of the authors ${ }^{12)}$ estimated nine areas on the causative fault of the 2011 Tohoku earthquake that generated strong-motion pulses (Fig. 3). These areas are referred to as the Strong-motion Pulse Generation Areas (SPGAs) in this article, as will be discussed later. Here we examine three of these SPGAs: SPGA4, SPGA7 and SPGA8, which are representative of off-Miyagi, off-Fukushima, and off-Ibaraki, respectively. The propagation of the pulses from these SPGAs is shown in Fig. 4 through Fig. 8. Among the four SPGAs off Miyagi, SPGA4 was selected because its effect is the most distinct 


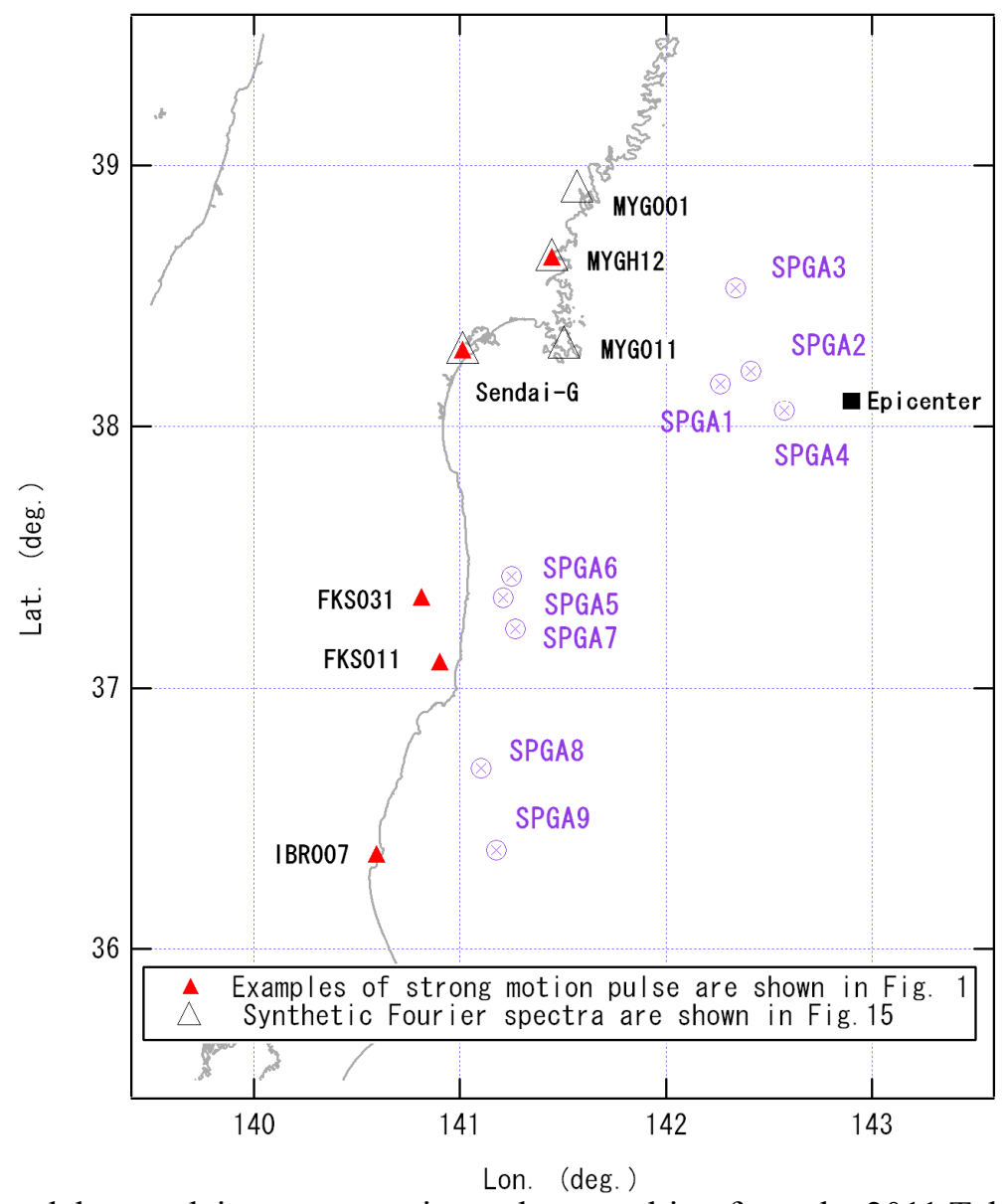

Fig. 3 A source model to explain strong-motion pulses resulting from the 2011 Tohoku earthquake ${ }^{12)}$, the strong motion stations that recorded the strong-motion pulses shown in Fig. 1 and those for which synthetic Fourier spectra are shown in Fig. 15.

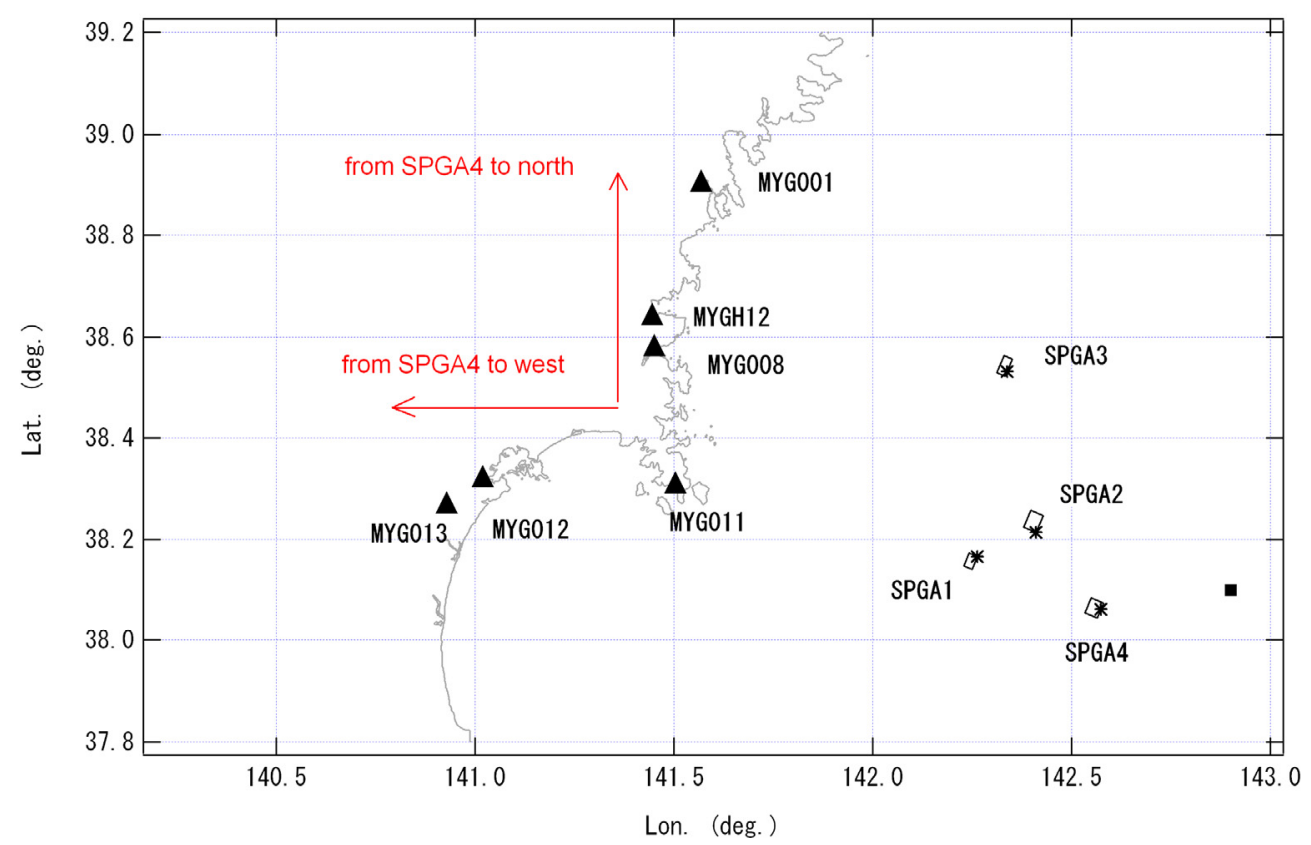

Fig. 4 Four SPGAs off Miyagi Prefecture (‘*) denotes the local rupture starting point) and the strong-motion stations that recorded the strong-motion pulses shown in Fig. 5. 


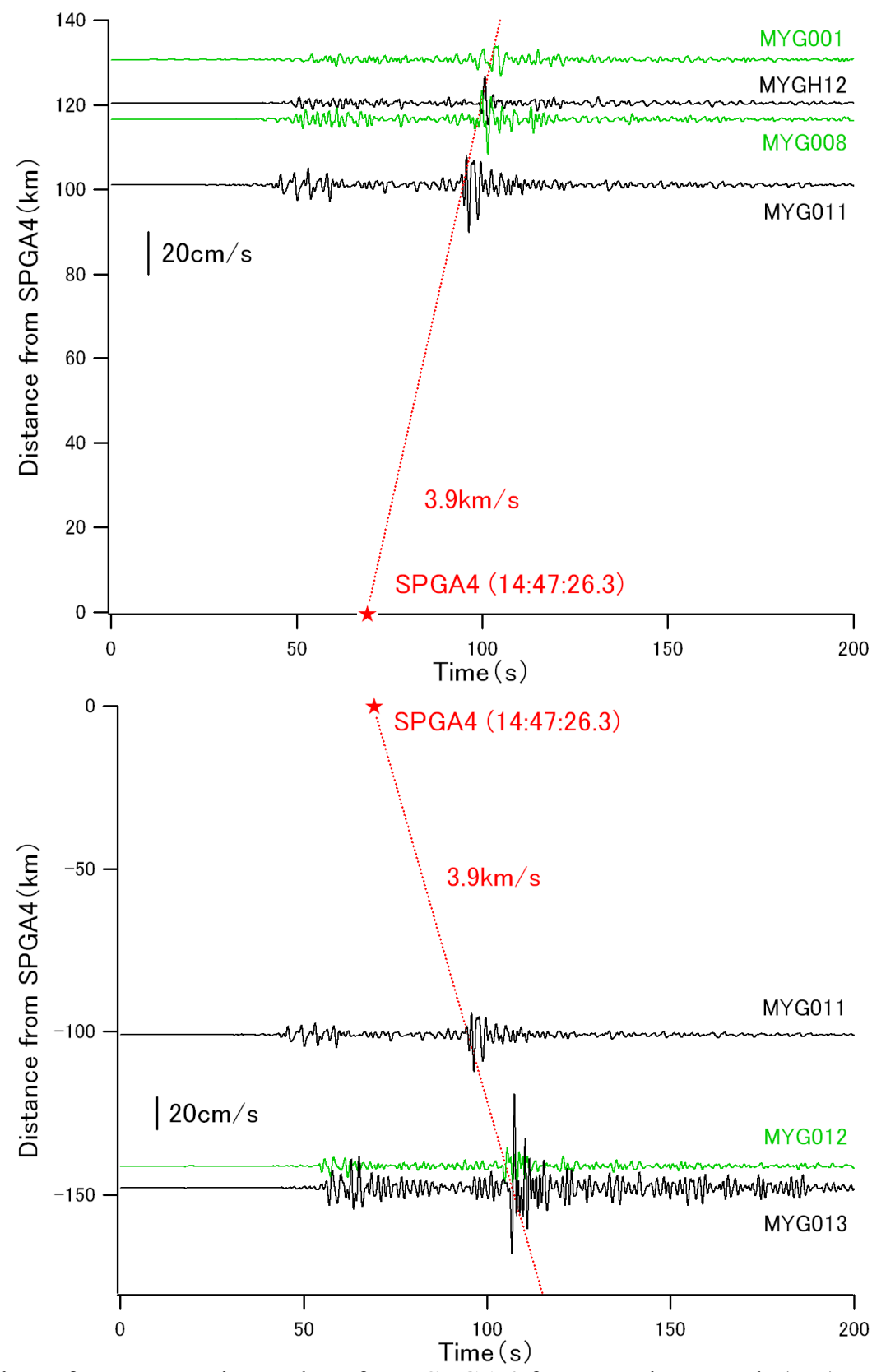

Fig. 5 Propagation of strong-motion pulses from SPGA4 from south to north (top) and from east to west (bottom). The left axis indicates the distance from SPGA4 to the stations. The bottom axis indicates the time from the initial rupture at the hypocenter. The waveforms are the velocity waveforms in the frequency range of $0.2-1 \mathrm{~Hz}$ in the NS component, with the exception that the EW component is shown for MYG011 where the amplitude of the NS component is small. The red dotted lines indicate the S-wave arrival time from SPGA4 with an assumed shear wave velocity of $3.9 \mathrm{~km} / \mathrm{s}$.

on the time history. SPGA7 and SPGA8 were selected for a similar reason.

Fig. 5 shows the propagation of the strong-motion pulse from SPGA4 off Miyagi Prefecture (Fig. 4). The top panel shows the successive arrival of the pulse at MYG011, MYG008, MYGH12, and MYG001, south to north, at 95-104 s after the hypocentral time. The bottom panel shows the successive arrival of the pulse at MYG011, MYG012, and MYG013, east to west, at 95-108 s after the hypocentral time. At MYG013, the pulse was significantly amplified because of the large site 

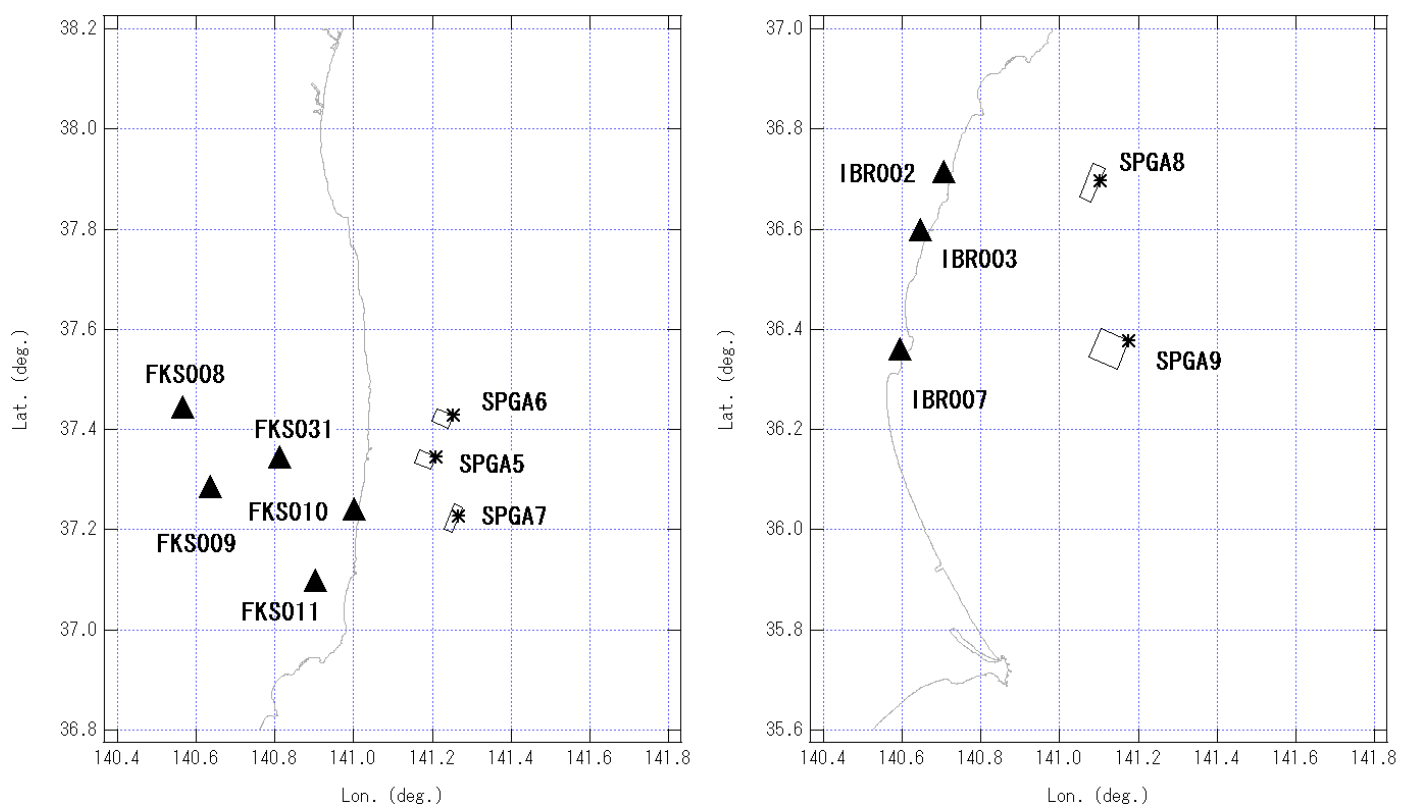

Fig. 6 SPGAs off Fukushima and Ibaraki Prefectures ( $* *$, denotes the local rupture starting point) and the strong motion stations that recorded the strong-motion pulses shown in Figs. 7 and 8.

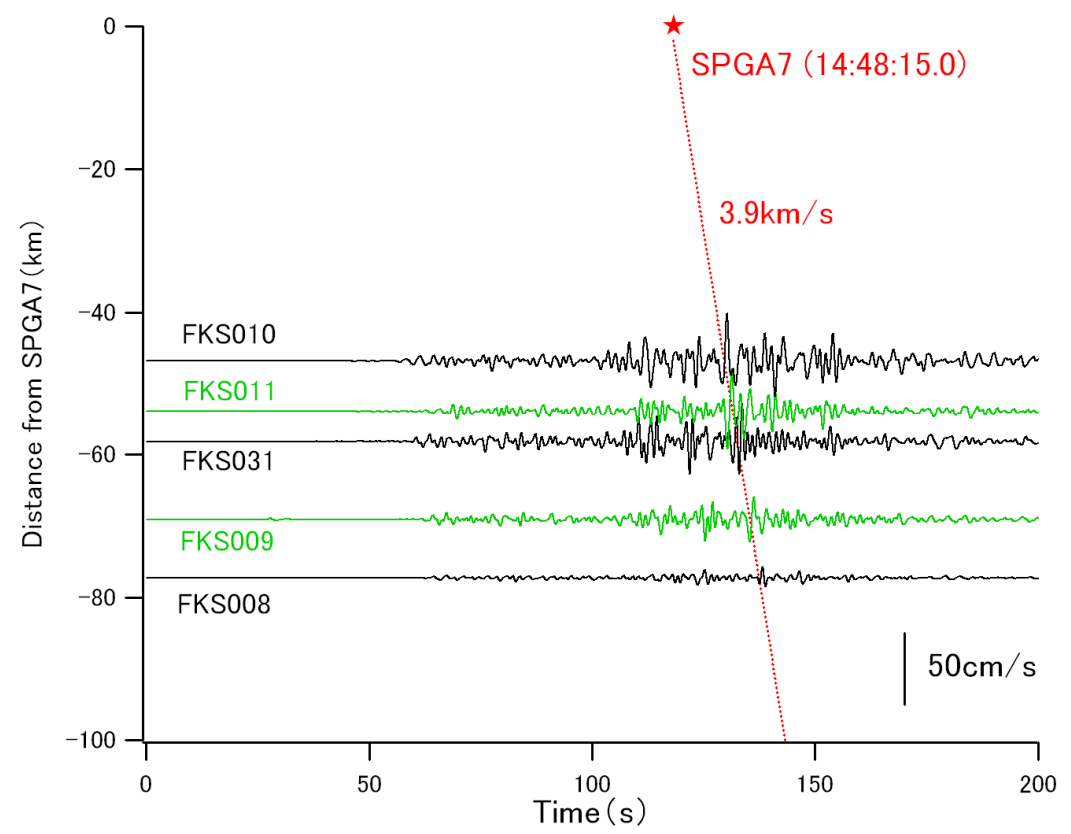

Fig. 7 Propagation of strong-motion pulses from SPGA7. The left axis indicates the distance from SPGA7 to the stations. The bottom axis indicates the time from the initial rupture at the hypocenter. The waveforms are the velocity waveforms in the frequency range of $0.2-1 \mathrm{~Hz}$ in the NS component, with the exception that the EW component is shown for FKS010 where the amplitude of the NS component is small. The red dotted line indicates the S-wave arrival time from SPGA7 with an assumed shear wave velocity of $3.9 \mathrm{~km} / \mathrm{s}$.

amplification factor ${ }^{13)}$. These observations clearly indicate that the strong-motion pulse has its origin on the fault. Similarly, the propagation of the strong-motion pulse from SPGA7 (Fig. 6) is shown in Fig. 7. Furthermore, the propagation of the strong-motion pulse from SPGA8 (Fig. 6) is shown in Fig. 8 . These figures also indicate that the strong-motion pulses originated from the fault. 


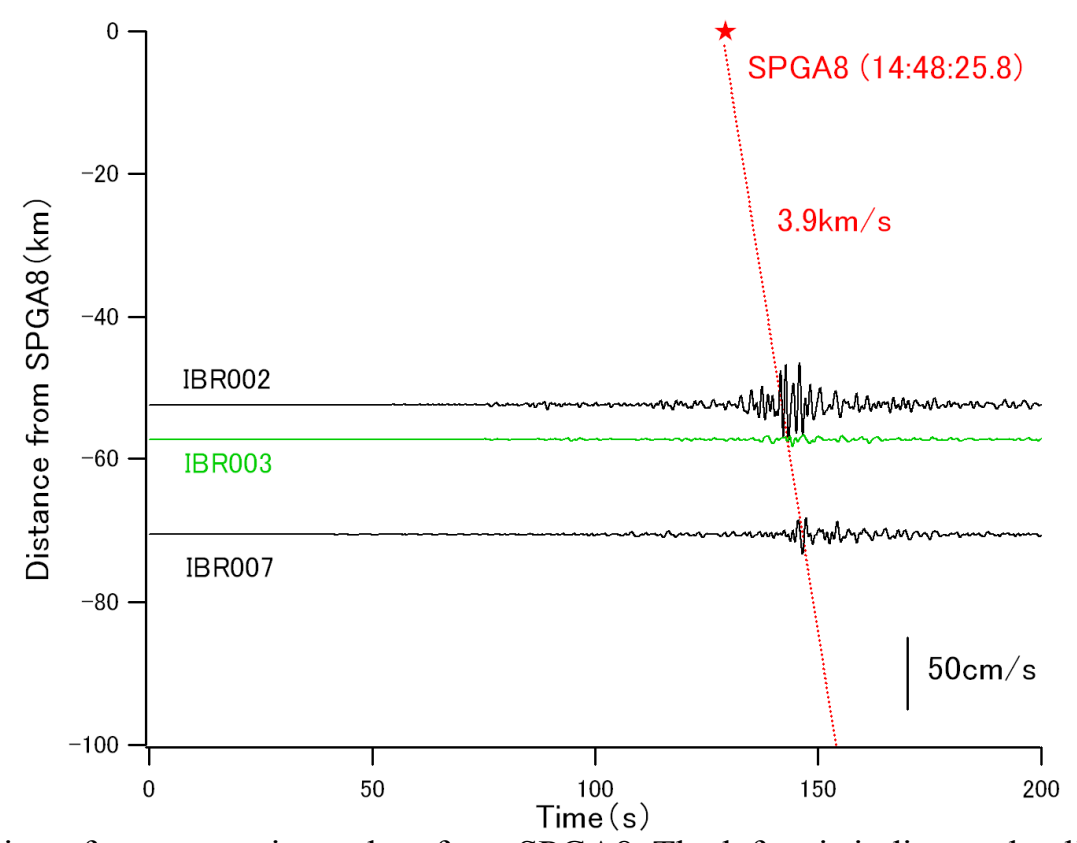

Fig. 8 Propagation of strong-motion pulses from SPGA8. The left axis indicates the distance from SPGA8 to the stations. The bottom axis indicates the time from the initial rupture at the hypocenter. The waveforms are the velocity waveforms in the frequency range of $0.2-1 \mathrm{~Hz}$ in the EW component. The red dotted line indicates the S-wave arrival time from SPGA8 with an assumed shear wave velocity of $3.9 \mathrm{~km} / \mathrm{s}$.
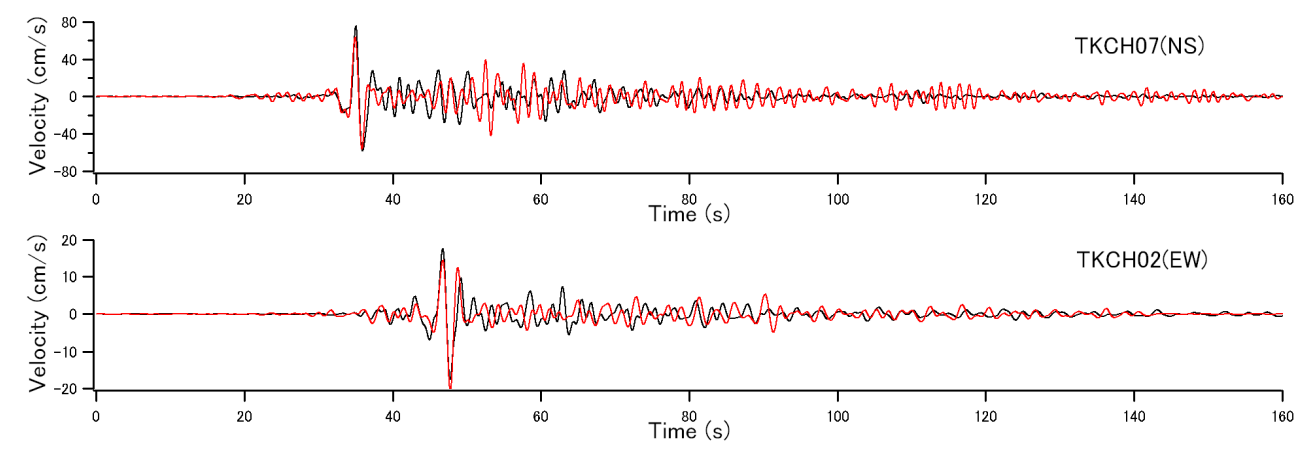

Fig. 9 Examples of strong-motion pulses observed during the 2003 Tokachi-oki earthquake (black lines) and the synthetic waveforms based on the SPGA model (3. ) (red lines). Both show the velocity waveforms in the frequency range of $0.2-1 \mathrm{~Hz}$.

\subsection{The 2003 Tokachi-oki earthquake}

The 2003 Tokachi-oki earthquake $\left(M_{\mathrm{w}} 7.9\right)$ is the first huge subduction earthquake recorded by the dense strong-motion networks ${ }^{122}$. The black traces in Fig. 9 show the velocity waveforms (surface records) in the frequency range of $0.2-1 \mathrm{~Hz}$ observed at two strong-motion stations in Tokachi Sub-Prefecture, namely, TKCH07 and TKCH02 (Fig. 10), during the 2003 Tokachi-oki earthquake. Again, distinct pulses can be seen in the waveforms. The pulses are similar to those generated by shallow crustal earthquakes (Fig. 2) in terms of the shape and the period. 


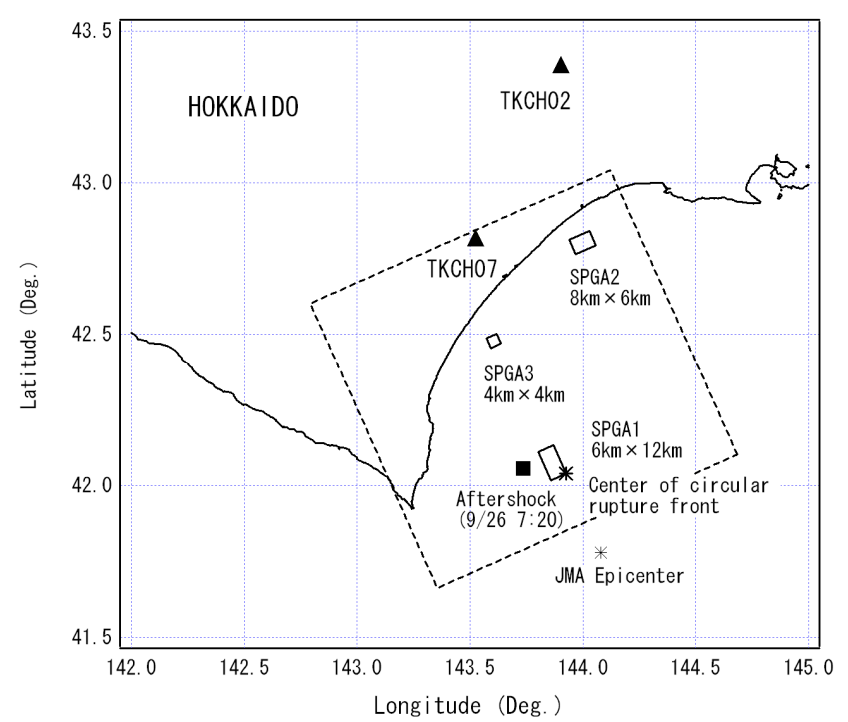

Fig. 10 A source model to explain the strong-motion pulses resulting from the 2003 Tokachi-oki earthquake $^{14)}$ and the strong-motion stations that recorded the strong-motion pulses shown in Fig. 9.

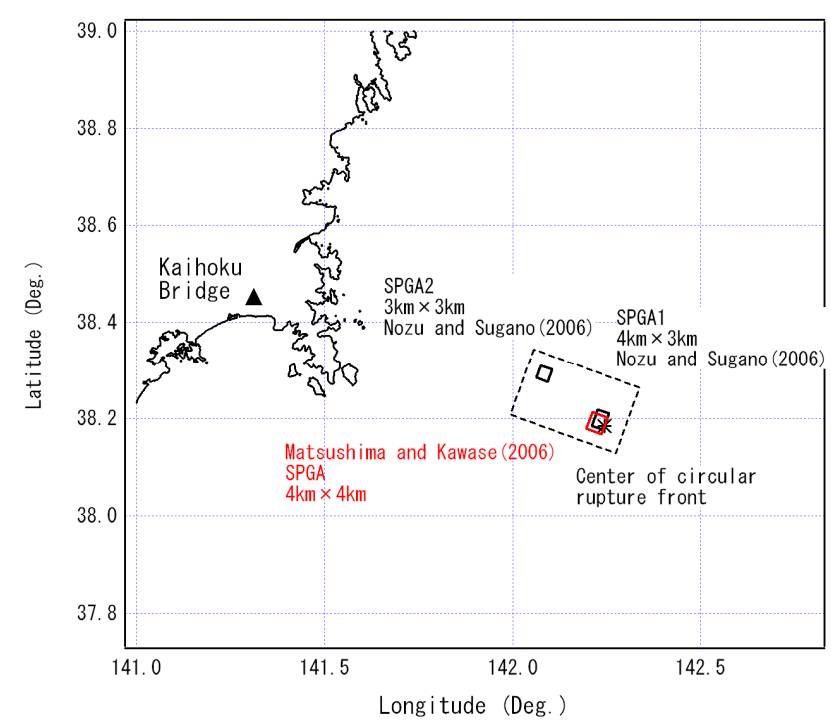

Fig. 11 Source models to explain strong-motion pulses resulting from the 1978 Miyagi-ken-oki earthquake and the location of the Kaihoku Bridge. The source models of Nozu and Sugano ${ }^{14)}$ and Matsushima and Kawase ${ }^{15)}$ are shown.

\subsection{The 1978 Miyagi-ken-oki earthquake}

During the 1978 Miyagi-ken-oki earthquake $\left(M_{\mathrm{w}} 7.6\right)$, the Public Works Research Institute, former Ministry of Construction, obtained strong-motion records ${ }^{10)}$ on the ground surface close to the Kaihoku Bridge in Ishinomaki City (Fig. 11). The black traces in Fig. 12 show the velocity waveforms in the frequency range of $0.2-1 \mathrm{~Hz}$ for the record. Again, distinct pulses can be seen in the waveforms. The pulses are similar to those generated by shallow crustal earthquakes (Fig. 2) in terms of the shape and the period. 

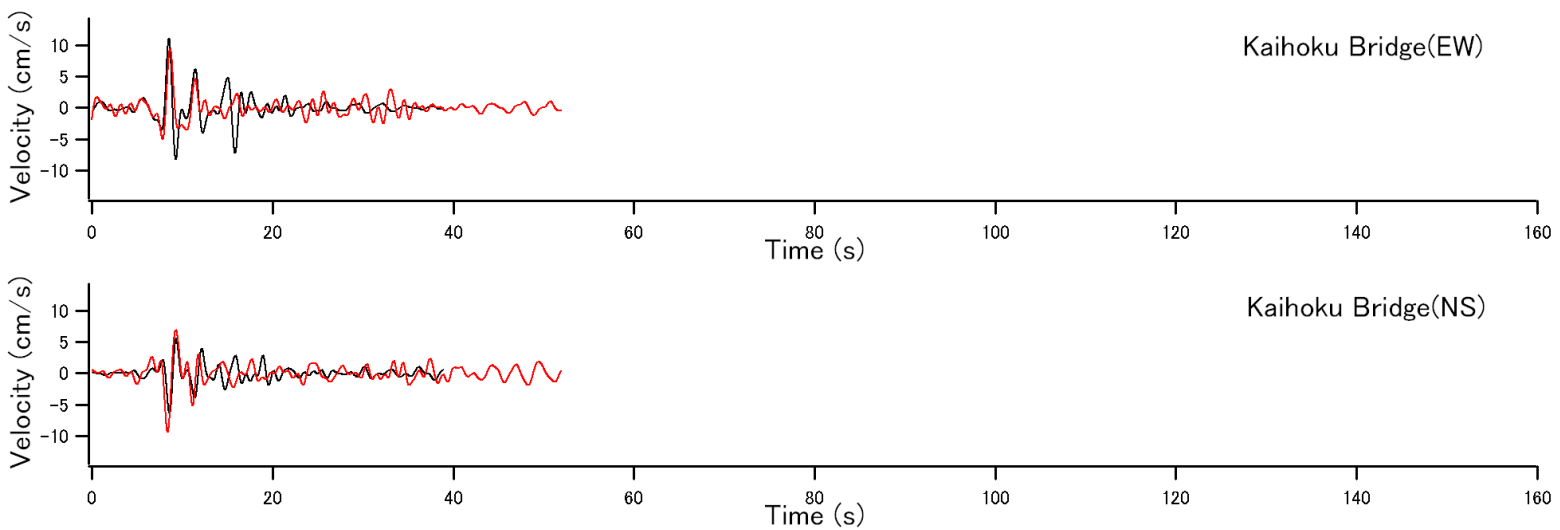

Fig. 12 Examples of strong motion-pulses observed during the 1978 Miyagi-ken-oki earthquake (black lines) and synthetic waveforms based on the SPGA model (3. ) (red lines). Both show the velocity waveforms in the frequency range of $0.2-1 \mathrm{~Hz}$. The scale used for the bottom axis is the same as in Figs. 1 and 2.

\section{SOURCE MODELS TO EXPLAIN STRONG MOTION PULSES GENERATED BY HUGE SUBDUCTION EARTHQUAKES}

In this section, conventional source models aiming at reproducing strong-motion pulses generated by huge subduction earthquakes are compiled.

\subsection{Compiled source models and subevent terminology}

In the construction of a source model, it would be ideal to be able to calculate strong ground motions in any frequency range accurately with just one source model. In reality, however, a source model which is intended to match strong-motion data uniformly over a wide frequency range may not be appropriate for reproducing strong-motion pulses.

Here, we present one example from the 2005 West Off Fukuoka Prefecture earthquake $\left(M_{\mathrm{w}} 6.5\right)$, although this example is of a shallow crustal earthquake. In terms of the asperity of this earthquake located south-east of the epicenter, Satoh and Kawase ${ }^{16)}$, who intended to reproduce broadband strong ground motions (in particular, envelopes of velocity and acceleration), used an asperity with the length of $10 \mathrm{~km}$, the width of $10 \mathrm{~km}$ and the area of $100 \mathrm{~km}^{2}$. On the other hand, Kawase et al. ${ }^{17)}$, who intended to reproduce strong-motion pulses with a period of about $1 \mathrm{~s}$, employed an asperity with the length of $4.1 \mathrm{~km}$, the width of $5.1 \mathrm{~km}$ and the area of $20.9 \mathrm{~km}^{2}$. While other studies were carried out on the same asperity ${ }^{18)}$, Kawase et al. succeeded in reproducing the time width and the amplitude of the strong-motion pulses observed south-east of the causative fault with highest accuracy. Recently, one of the authors ${ }^{19)}$ also developed a source model for the same earthquake and successfully reproduced waveforms at many strong-motion stations by using an asperity similar in size to that of Kawase et al.

The same should be applicable for the source model for huge subduction earthquakes. Source models composed of Strong Motion Generation Areas ${ }^{20)}$ (SMGAs) have been proposed for huge subduction earthquakes. For the 2011 Tohoku earthquake, several SMGA models ${ }^{621) 22(23) 24) 25}$ have been proposed. In these source models, SMGAs have a dimension of several tens of kilometers and hence a rupture duration of about 10 to $30 \mathrm{~s}$. Therefore, these SMGAs are too large to explain strong-motion pulses with a time width around $2 \mathrm{~s}$, even if we consider directivity. Thus, we need to consider a more compact region within the SMGAs.

Matsushima and Kawase ${ }^{15)}$ in their study of the 1978 Miyagi-ken-oki earthquake showed that, by using a rectangular region with dimensions of about $4 \mathrm{~km}$, they can reproduce the amplitude and the period of the strong-motion pulse observed at the Kaihoku Bridge. Because the rectangular region was 
Table 1 Source models for simulating strong-motion pulses generated by huge subduction earthquakes and smaller subduction earthquakes

\begin{tabular}{|c|c|c|c|c|c|c|c|c|c|c|c|c|}
\hline \multirow[t]{2}{*}{ Earthquake } & \multirow{2}{*}{$\begin{array}{l}\mathrm{M}_{0} * \\
\mathrm{Nm}\end{array}$} & \multirow[t]{2}{*}{$M_{w}$} & \multirow[t]{2}{*}{ Reference } & \multirow{2}{*}{$\begin{array}{l}\text { Name in the } \\
\text { reference }\end{array}$} & \multirow{2}{*}{$\begin{array}{l}\text { Name in } \\
\text { this study }\end{array}$} & \multirow{2}{*}{$\begin{array}{l}\rho \\
\mathrm{kg} / \mathrm{m}^{3}\end{array}$} & \multirow{2}{*}{$\frac{\beta}{\mathrm{km} / \mathrm{s}}$} & \multirow{2}{*}{$\begin{array}{l}\mathrm{Vr} \\
\mathrm{km} / \mathrm{s}\end{array}$} & \multicolumn{2}{|c|}{$\mathrm{S}_{\mathrm{SPGA}} * * \mathrm{M}_{O S P G A}$} & \multirow{2}{*}{$\begin{array}{l}A_{S P G A} \\
\mathrm{Nm} / \mathrm{s}^{2}\end{array}$} & \multirow{2}{*}{$\begin{array}{l}E_{S P G A} \\
N^{2} m^{2} / s^{3}\end{array}$} \\
\hline & & & & & & & & & $\mathrm{km}^{2}$ & $\mathrm{Nm}$ & & \\
\hline The 1968 & $2.80 \mathrm{E}+21$ & 8.2 & 14) & Asperity-1 & SPGA1 & $3.1 \mathrm{E}+03$ & 3.9 & 3.0 & 128 & $7.20 \mathrm{E}+19$ & $1.47 \mathrm{E}+20$ & $1.89 \mathrm{E}+39$ \\
\hline \multirow[t]{2}{*}{ Tokachi-oki earthquake } & & & & Asperity-2 & SPGA2 & $3.1 \mathrm{E}+03$ & 3.9 & 3.0 & 64 & $1.80 \mathrm{E}+19$ & $7.36 \mathrm{E}+19$ & $3.35 \mathrm{E}+38$ \\
\hline & & & & Asperity -3 & SPGA3 & $3.1 \mathrm{E}+03$ & 3.9 & 3.0 & 4 & $2.30 \mathrm{E}+18$ & $1.50 \mathrm{E}+20$ & $3.50 \mathrm{E}+38$ \\
\hline The 1978 & $3.10 \mathrm{E}+20$ & 7.6 & 15) & SA & SPGA & $3.1 \mathrm{E}+03$ & 3.9 & 3.0 & 16 & $1.20 \mathrm{E}+19$ & - & \\
\hline \multicolumn{2}{|c|}{ Miyagi-ken-oki earthquake } & & 14) & Asperity-1 & SPGA1 & $3.1 \mathrm{E}+03$ & 3.9 & 3.0 & 12 & $1.20 \mathrm{E}+19$ & $2.62 \mathrm{E}+20$ & $1.83 E+39$ \\
\hline & & & & Asperity-2 & SPGA2 & $3.1 \mathrm{E}+03$ & 3.9 & 3.0 & 9 & $4.80 \mathrm{E}+18$ & $1.40 \mathrm{E}+20$ & $4.51 \mathrm{E}+38$ \\
\hline The 2003 & $8.21 \mathrm{E}+20$ & 7.9 & 14) & Asperity-1 & SPGA1 & $3.1 \mathrm{E}+03$ & 3.9 & 3.0 & 72 & $4.20 E+19$ & $1.53 \mathrm{E}+20$ & $1.53 \mathrm{E}+39$ \\
\hline \multirow[t]{2}{*}{ Tokachi-oki earthquake } & & & & Asperity-2 & SPGA2 & $3.1 \mathrm{E}+03$ & 3.9 & 3.0 & 48 & $2.10 \mathrm{E}+19$ & $1.14 \mathrm{E}+20$ & $7.01 \mathrm{E}+38$ \\
\hline & & & & Asperity -3 & SPGA3 & $3.1 \mathrm{E}+03$ & 3.9 & 3.0 & 16 & $2.40 \mathrm{E}+18$ & $3.92 \mathrm{E}+19$ & $4.76 \mathrm{E}+37$ \\
\hline The 2005 & $5.43 \mathrm{E}+19$ & 7.1 & 26) & Asperity-1 & SPGA1 & $3.1 \mathrm{E}+03$ & 3.9 & 3.0 & 10.5 & $5.00 \mathrm{E}+18$ & $1.25 \mathrm{E}+20$ & $3.89 \mathrm{E}+38$ \\
\hline \multicolumn{2}{|c|}{ Miyagi-ken-oki earthquake } & & & Asperity-2 & SPGA2 & $3.1 \mathrm{E}+03$ & 3.9 & 3.0 & 5 & $2.00 \mathrm{E}+18$ & $1.05 \mathrm{E}+20$ & $1.89 \mathrm{E}+38$ \\
\hline The 2011 & $3.80 \mathrm{E}+22$ & 9.0 & 12) & SA1_1 & SPGA1 & $3.1 \mathrm{E}+03$ & 3.9 & 3.0 & 6 & $8.00 \mathrm{E}+18$ & $3.49 \mathrm{E}+20$ & $2.30 \mathrm{E}+39$ \\
\hline \multirow[t]{8}{*}{ Tohoku earthquake } & & & & SA1_2 & SPGA2 & $3.1 \mathrm{E}+03$ & 3.9 & 3.0 & 12 & $8.00 E+18$ & $1.74 \mathrm{E}+20$ & $8.14 \mathrm{E}+38$ \\
\hline & & & & SA1_3 & SPGA3 & $3.1 \mathrm{E}+03$ & 3.9 & 3.0 & 8 & $4.00 E+18$ & $1.31 \mathrm{E}+20$ & $3.74 \mathrm{E}+38$ \\
\hline & & & & $\mathrm{SA} 2$ & SPGA4 & $3.1 \mathrm{E}+03$ & 3.9 & 3.0 & 10.5 & $2.10 \mathrm{E}+19$ & $5.23 E+20$ & $6.85 E+39$ \\
\hline & & & & SA3_1 & SPGA5 & $3.1 \mathrm{E}+03$ & 3.9 & 3.0 & 12 & $3.00 E+18$ & $6.54 \mathrm{E}+19$ & $1.14 \mathrm{E}+38$ \\
\hline & & & & SA3_2 & SPGA6 & $3.1 \mathrm{E}+03$ & 3.9 & 3.0 & 12 & $3.00 \mathrm{E}+18$ & $6.54 \mathrm{E}+19$ & $1.14 \mathrm{E}+38$ \\
\hline & & & & SA3_3 & SPGA7 & $3.1 \mathrm{E}+03$ & 3.9 & 3.0 & 12 & $5.00 \mathrm{E}+18$ & $1.09 \mathrm{E}+20$ & $3.18 \mathrm{E}+38$ \\
\hline & & & & SA4 & SPGA8 & $3.1 \mathrm{E}+03$ & 3.9 & 3.0 & 24 & $9.00 \mathrm{E}+18$ & $9.81 \mathrm{E}+19$ & $3.64 \mathrm{E}+38$ \\
\hline & & & & SA5 & SPGA9 & $3.1 \mathrm{E}+03$ & 3.9 & 3.0 & 49 & $2.00 \mathrm{E}+19$ & $1.07 \mathrm{E}+20$ & $6.17 \mathrm{E}+38$ \\
\hline
\end{tabular}

* $\mathrm{M}_{0}$ is basically based on the $\mathrm{F}-$ net, except for the 1968 Tokachi-oki, the 1978 Miyagi-ken-oki and the 2011 Tohoku earthquakes,

for which $M_{0}$ is based on Kanamori (1971), Seno et al. (1980) and Koketsu et al. (2011), respectively.

**T The estimated $\mathrm{S}_{\mathrm{SPGA}}$ depends on the assumed $\mathrm{Vr}$ and it may involve errors.

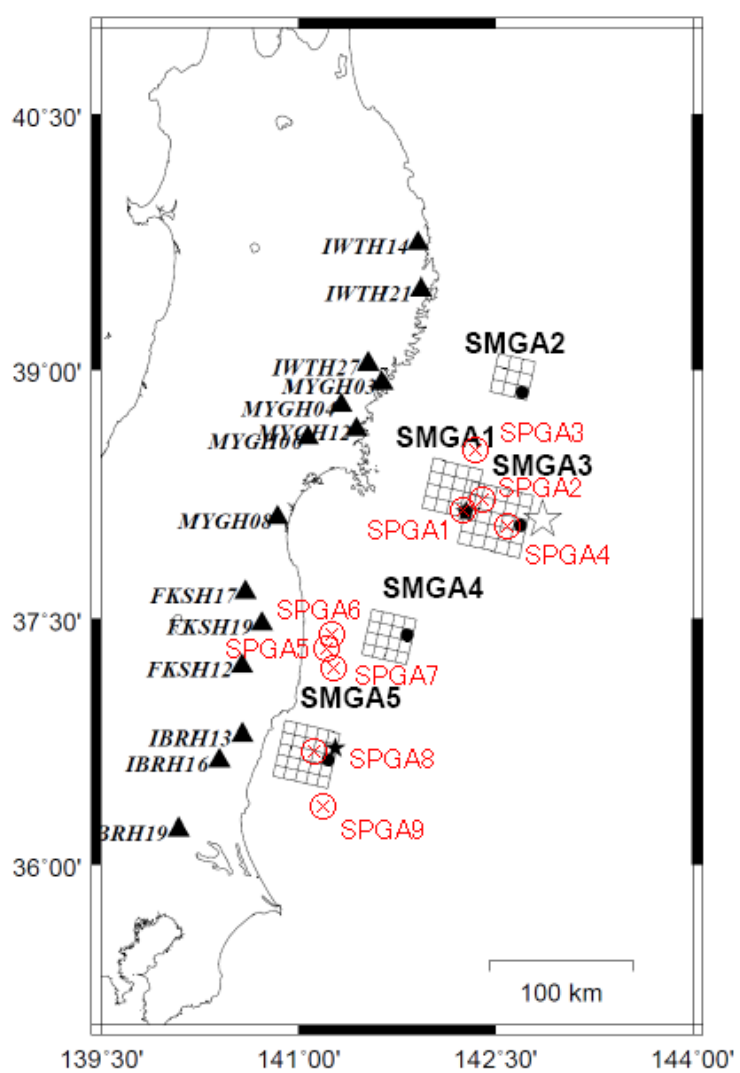

Fig. 13 Locations of the SPGAs ${ }^{12)}$ and SMGAs ${ }^{24)}$ estimated for the 2011 Tohoku earthquake 
significantly smaller than the asperities (SMGAs in the current terminology) generally assumed for an earthquake of this size, they regarded the rectangular region as expressing heterogeneity within the asperity, rather than being an asperity itself, and referred to it as a "super asperity". One of the authors $^{12)}$, in the effort to reproduce strong-motion pulses for the 2011 Tohoku earthquake, introduced rectangular regions with a dimension of several kilometers and referred to them as "super asperities", following the definition of Matsushima and Kawase ${ }^{15}$.

Thus, a series of source models with much more compact regions than the conventional SMGAs have been proposed over the last decade. These source models are the focus of this article. Because we do not have sufficient data from huge subduction earthquakes, smaller earthquakes such as the 1978 Miyagi-ken-oki earthquake $\left(M_{\mathrm{w}} 7.6\right)$ are also included in our study although strictly speaking they are not "huge" subduction earthquakes. The source models for simulating strong motion pulses generated by huge subduction earthquakes and smaller subduction earthquakes are compiled in Table 1.

In this study, the name of the subevents that constitute the source models was determined as follows. As mentioned above, the term "super asperity" was used by Matsushima and Kawase ${ }^{15}$ and Nozu ${ }^{12)}$. The definition of the term "asperity" itself, however, is currently undergoing a transition. The term "asperity" originally referred to a region on the fault which is locked in the inter-seismic period where the coseismic slip is large, and which becomes the source of strong ground motion. In terms of the 2011 Tohoku earthquake, however, the region of large slip does not necessarily coincide with the region of strong motion generation ${ }^{6}$; therefore, recently there is a tendency to use the term "asperity" to denote a region with a large slip. Thus, in this article, the region on the fault which generated the strong-motion pulse is referred to as a "Strong-motion Pulse Generation Area (SPGA)". Therefore, the subevents that were originally called the "super asperities" in Matsushima and Kawase ${ }^{15)}$ and Nozu ${ }^{12)}$ will be referred to as the "SPGAs" in this article. In earlier studies ${ }^{1426)}$, source models were also developed to explain strong-motion pulses for the 1968 Tokachi-oki, 1978 Miyagi-ken-oki, 2003 Tokachi-oki, and 2005 Miyagi-ken-oki earthquakes. Although the subevents of those source models were originally called the "asperities", they will be referred to as the "SPGAs" in this article.

The locations of the SPGAs ${ }^{12)}$ and SMGAs ${ }^{24)}$ estimated for the 2011 Tohoku earthquake are compared in Fig. 13. Each SPGA is located within or close to one of the SMGAs. In many of the other earthquakes mentioned here, the SPGAs are involved in the SMGAs. Thus, the SPGAs can be regarded as expressing heterogeneity within the SMGAs. Noting the fact that the estimated locations of the SPGAs and SMGAs inevitably involve errors, the idea that "the SPGAs are the expressions of the heterogeneity within the SMGAs" does not contradict the fact that some SPGAs are estimated outside the SMGAs for the 2011 Tohoku earthquake.

\subsection{Method of strong-motion simulation used for each source model}

Except for the source model of Matsushima and Kawase ${ }^{15)}$ for the 1978 Miyagi-ken-oki earthquake, all of the other source models employ strong-motion simulation based on the site-specific amplification and phase characteristics ${ }^{2728) 29}$. The essence of the method is to calculate the ground motions from an SPGA by generating the Green's functions considering the source spectrum that follows the omega-square model ${ }^{30)}$, the path effect, and the empirical site amplification factor ${ }^{13)}$ and by superposing it following the method of Irikura $e t a l^{31)}$. Thus, the resultant source spectrum of each SPGA basically follows the omega-square model and one can define the low-frequency flat level of the displacement source spectrum and the high-frequency flat level of the acceleration source spectrum, denoted here as $M_{0 \mathrm{SPGA}}$ and $A_{\mathrm{SPGA}}$, respectively, and listed in Table 1 . The details of the simulation can be found in the literature ${ }^{27) 28(29)}$.

The simulation method ${ }^{272829)}$ can account for the later phases caused by the path and site effects. When constructing a source model in this method, multiple SPGAs are introduced to explain pulses on the waveforms that cannot be explained as a path effect or a site effect.

In the source model of Matsushima and Kawase ${ }^{15)}$ for the 1978 Miyagi-ken-oki earthquake, theoretical Green's functions for a layered half-space were used. Therefore, $A_{\text {SPGA }}$ was not specified in their model and is not included in Table 1. 


\subsection{Accuracy of the calculation of strong-motion pulses based on each source model}

In the following, the accuracy of the calculation of strong-motion pulses based on each source model is reviewed.

The source model for the 2011 Tohoku earthquake ${ }^{12)}$ employs nine SPGAs with dimension of several kilometers off the east coast of Tohoku from Miyagi to Ibaraki (Fig. 3) and accurately reproduces velocity waveforms in the frequency range of $0.2-1 \mathrm{~Hz}$ including strong-motion pulses. For example, the red traces in Fig. 1 show the calculated strong-motion pulses at five stations (2.1) based on the source model. The simulated waveforms show a fairly good agreement with the observed waveforms. Although only the results for the NS components are shown in Fig. 1, those for the EW components are also satisfactory. The overestimation in the later phases at IBR007 may be caused by nonlinear soil behavior during the 2011 Tohoku earthquake.

The source model for the 2003 Tokachi-oki earthquake ${ }^{14)}$ employs three SPGAs; one is east of Cape Erimo, one is off the coast of Kushiro, and the other is at a depth along the coast of Tokachi Sub-Prefecture (Fig. 10). It utilizes the results of a waveform inversion ${ }^{32)}$, and accurately reproduces velocity waveforms in the frequency range of $0.2-1 \mathrm{~Hz}$ including strong-motion pulses. For example, the red traces in Fig. 9 show the calculated strong-motion pulses at two stations (2. 2) based on the source model; these show a fairly good agreement with the observed waveforms. Only the results for the NS components are shown in Fig. 9; however the results for the EW components are also satisfactory. It should be noted that an earlier study ${ }^{33)}$ reproduced the strong-motion pulse at TKCH07 by taking into account an SMGA $(20 \times 24 \mathrm{~km})$ and forward directivity effects rather than an SPGA (6 $\times 12 \mathrm{~km}$; Fig. 10) ${ }^{14)}$. In our study, however, the source model in Fig. $10^{14)}$ is used because it reproduces velocity waveforms for the frequency range of $0.2-1 \mathrm{~Hz}$ at a larger number of stations.

The source model for the 1978 Miyagi-ken-oki earthquake ${ }^{14)}$ employs two SPGAs (Fig. 11) and accurately reproduces two strong-motion pulses observed at the Kaihoku Bridge (Fig. 12). The SPGA proposed by Matsushima and Kawase ${ }^{15}$ for the same earthquake is also plotted in Fig. 11. Because their SPGA is almost at the same location as SPGA1 ${ }^{14)}$, they should correspond to each other. Their SPGA and our SPGA1 both reproduce the first of the two strong-motion pulses observed at the Kaihoku Bridge. Moreover, both have exactly the same seismic moment and approximately the same area (Table 1); their SPGA has an area of $16 \mathrm{~km}^{2}$ whereas SPGA1 has an area of $12 \mathrm{~km}^{2}$. Although the two studies employ different methods of strong-motion simulation, the estimated sizes of the SPGA do not differ significantly. This fact may indicate that the time width of a strong-motion pulse is controlled mainly by the rupture duration of the SPGA and does not depend on the simulation method. Another factor that may have contributed to the similarity of the results may be the common rupture velocity (Table 1) assumed in these studies. Because the SPGA of Matsushima and Kawase ${ }^{15}$ corresponds to SPGA1 in Fig. $11^{14)}$, the two SPGAs in Fig. $11^{14)}$ are considered in the ensuing analysis.

Nozu and Sugano ${ }^{14)}$ also proposed an SPGA model for the 1968 Tokachi-oki earthquake $\left(M_{\mathrm{w}} 8.2\right)$ (not shown here for brevity). In the strong-motion records obtained at the Port of Hachinohe and the Port of Aomori during the earthquake, the pulses from the source and the later phases have approximately the same amplitude; therefore, the pulse from the source is not necessarily dominant in the waveforms. In the next section we consider the source model because it can explain the waveforms in the frequency range of $0.2-1 \mathrm{~Hz}$ including the pulse from the source and the later phases. The source model for the 2005 Miyagi-ken-oki earthquake ${ }^{26}$ is also considered because it can explain the strong-motion pulses observed at the Kaihoku Bridge.

\section{PARAMETERS TO BE USED FOR SCALING OF SPGA}

It is significantly important to investigate the relation between the SPGA parameters and the size of the earthquake for the purpose of predicting strong ground motions for anticipated huge subduction earthquakes such as those along the Nankai Trough. In this section, we investigate what kind of 
parameters should be used for the scaling of the SPGAs.

\subsection{Time-domain parameters}

The strong-motion pulses are defined by the amplitude and the time width of the pulses (See Figs. 1, 9, and 12). Each strong-motion pulse, however, varies according to the distance it travels and the site effect. Hence, the observed amplitude and time width cannot be directly used as source parameters.

Therefore, we intend to remove the path and site effects from the observed strong-motion pulse and obtain a velocity waveform on the bedrock at a unit distance. It is necessary, however, to deconvolve the observed waveforms not only in terms of the Fourier amplitude but also in terms of the Fourier phase. This operation can result in significant errors and is not straightforward. Thus, as an alternative method, the velocity waveform on the bedrock at a unit distance is calculated based on the source models in Table 1. Once the calculated waveform is convolved with the path and site effects, it equals the synthetic waveform at the strong-motion station; the synthetic waveform agrees well with the observed waveform for the frequency range of $0.2-1 \mathrm{~Hz}$ (see 3. 3). Thus, the calculated waveform is equivalent to a waveform that can be obtained by removing the path and site effects from the observed waveform.

We recognize that the pulse width of the observed waveform is basically equivalent to that of the waveform on the bedrock. However, it can be ambiguous when a later phase due to the path or site effects arrives immediately after the direct S-wave. In addition, the response of the sediment may act as a kind of high-cut filter which may result a wider pulse at the surface. Thus, it is still meaningful to consider the pulse width on the bedrock.

Thus, we calculated the velocity waveforms on the bedrock at a unit distance from SPGA4 based on the source model in Fig. 3 for the two strong-motion stations MYGH12 and Sendai-G (Fig. 1). The results are shown in Fig. 14. The velocity waveform was calculated by using the same method as used in the development of the source model ${ }^{122728) 29}$. The resultant waveforms for the two stations are slightly different because of the difference of the azimuth and the take-off angle.

Fig. 14 shows the waveforms that are multiplied by the coefficient $4 \pi \rho \beta^{3} / R_{\theta \varphi} / F S / P R T I T N$, where $\rho$ is the density, $\beta$ is the shear wave velocity, $R_{\theta \varphi}$ is the radiation coefficient, $F S$ is a factor accounting for the amplification due to the free surface and PRTITN is a factor accounting for the partition of the shear-wave energy into two horizontal components. This coefficient adjusts the waveform so that the Fourier spectrum of the waveform equals the velocity source spectrum.

The "velocity waveforms on the bedrock at a unit distance" were also calculated for other SPGAs in a similar way. Because the waves do not include the distance effect or the site effect, the amplitude and time width of the pulse can be regarded as expressing the source effect. Therefore, they may be used for the scaling of the SPGAs.

\subsection{Frequency-domain parameters}

As mentioned above, the amplitude and time width of the "velocity waveforms on the bedrock at a unit distance" may be used for the scaling of the SPGAs. It is generally difficult, however, to discuss the scaling of the SPGA parameters with respect to the size of the entire earthquake (i.e., the moment magnitude $M_{\mathrm{w}}$ ) when using the parameters of individual SPGAs involved in one earthquake, because the parameters of the individual SPGAs can vary significantly. In the following, the scaling is discussed based on the sum of the acceleration spectra or the radiated energy (see below) for all the SPGAs involved in one earthquake. It is difficult to obtain the sum of the time-domain parameters, whereas it is possible to obtain the sum of the frequency-domain parameters such as the high-frequency level or the radiated energy for all the SPGAs involved in one earthquake as long as we assume that the source spectra for the individual SPGAs follow the omega-square model ${ }^{834) \text {. }}$ 


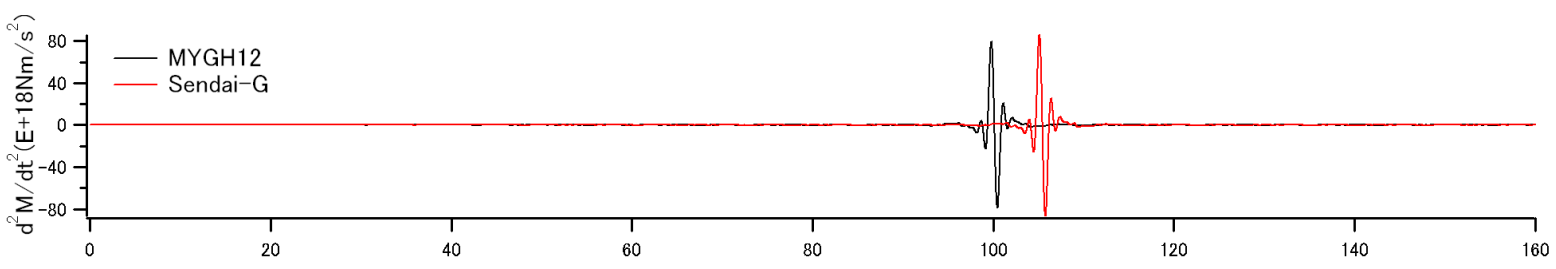

Fig. 14 The velocity waveforms on the bedrock at a unit distance from SPGA4 based on the source model in Fig. 3 for the two strong-motion stations MYGH12 and Sendai-G

For this purpose, first, the time-domain parameters, i.e., the amplitude and the time width, were transformed into frequency-domain parameters. Because the waveforms obtained in 4.1 are the velocity waveforms, their Fourier spectra, i.e., the velocity source spectra, approach zero at the lower and higher frequencies and have a peak in the intermediate frequencies. It is therefore possible to transform the time width and the amplitude in the time domain to the peak frequency $f_{\text {peak }}$ and the peak value $V_{\max }$ of the velocity source spectrum, respectively. Thus, the "velocity waveforms on the bedrock at a unit distance" were Fourier-transformed and $f_{\text {peak }}$ and $V_{\max }$ were calculated for all the SPGAs in Table 1 . Then, the parameters $f_{\text {peak }}$ and $V_{\max }$ were averaged for all the stations that were used in the construction of the source models.

Next, we examined whether it is appropriate to assume that the source spectra for the individual SPGAs follow the omega-square model. A velocity source spectrum that follows the omega-square model is given by

$$
\eta f)=M_{0} \frac{2 \pi f}{1+\left(\frac{f}{f_{c}}\right)^{2}},
$$

where $V(f)$ is the velocity source spectrum and $f_{\mathrm{c}}$ is the corner frequency. Eq. (1) takes the peak value $\pi f_{\mathrm{c}} M_{0}$ at $f=f_{\mathrm{c}}$. Because Eq. (1) involves only two unknown parameters, i.e., $M_{0}$ and $f_{\mathrm{c}}$, by imposing the condition that "Eq. (1) takes the peak value $V_{\max }$ at $f=f_{\text {peak }}$ ", Eq. (1) is determined. Then, it was multiplied by the path effect and the site amplification factor ${ }^{13)}$ and compared with the observed Fourier spectrum.

For this comparison, it is necessary to use a section of the observed waveform which is affected by a single SPGA. According to the study based on the source model in Fig. 3, the contribution from SPGA4 is dominant in the second wave packet ${ }^{6)}$ of the observed waveforms at MYG001, MYGH12, MYG011, and Sendai-G. Thus, the Fourier spectra from the second wave packet recorded at these stations were compared to the source spectra multiplied by the path effect and the site amplification factor. In particular, at MYGH12, the waveform after $80 \mathrm{~s}$ in Fig. 1 was used. At Sendai-G, the waveform after $65 \mathrm{~s}$ in Fig. 1 was used. The results are shown in Fig. 15. The agreement between the observed and the calculated Fourier spectra is quite satisfactory in the frequency range of $0.2-10 \mathrm{~Hz}$, indicating that the source spectrum of SPGA4 follows the omega-square model ( $f_{\max }$ is not considered in this calculation).

For the other SPGAs of the 2011 Tohoku earthquake, it is difficult to find a section of the observed waveform to which only one SPGA contributed. If we assume, however, that the source spectra of the individual SPGAs follow Eq. (1) and if the calculated Fourier spectra for the nine SPGAs are summed up by taking into account the arrival time information, then the resultant Fourier spectra agree well with the observed spectra in the frequency range of $0.2-10 \mathrm{~Hz}$ (Fig. 16). The same can be said for the other earthquakes listed in Table 1. This suggests that the source spectrum of each SPGA follows the omega-square model, although this assumption was only validated within the framework of a forward modeling.

Furthermore, if we interpolate the low-frequency level $M_{0 \mathrm{SPGA}}$ and the high-frequency level $A_{\mathrm{SPGA}}$ in Table 1 with Eq. (1), then the resulting values of $f_{\text {peak }}$ and $V_{\max }$ agree well with those obtained from the "velocity waveforms on the bedrock at a unit distance" as shown in Fig. 17. Thus, the discussion on the scaling of $f_{\text {peak }}$ and $V_{\max }$ obtained from the "velocity waveforms on the bedrock at a unit distance" can be converted to a discussion on the scaling of $M_{0 \mathrm{SPGA}}$ and $A_{\mathrm{SPGA}}$ in Table 1.

Moreover, the integral of the squared velocity source spectrum with respect to frequency is 

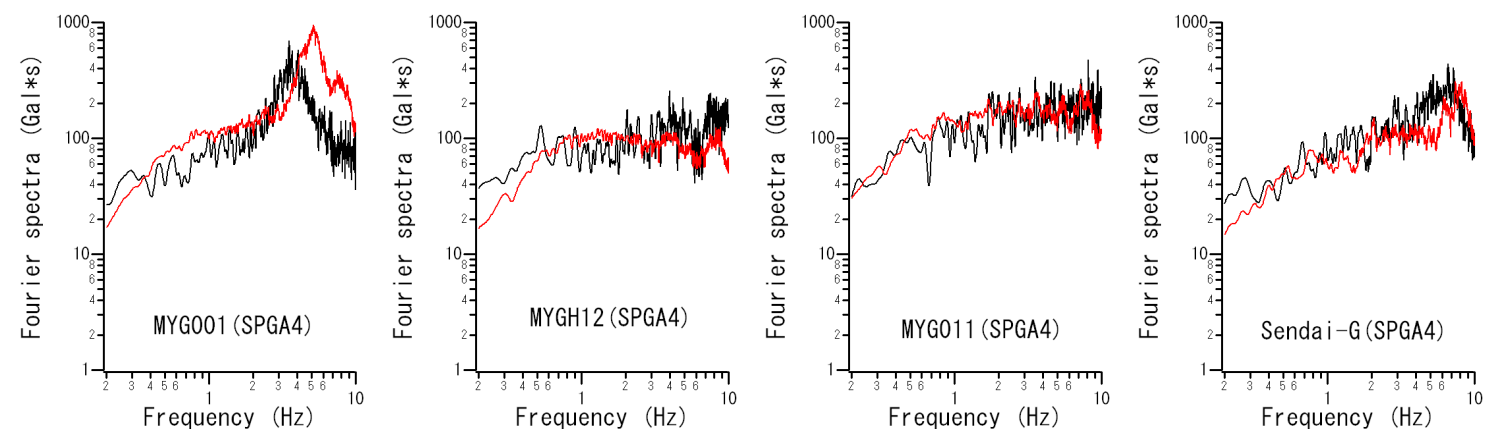

Fig. 15 The Fourier spectra of the observed waveforms during the 2011 Tohoku earthquake (black) and the synthetic Fourier spectra assuming that the source spectrum of SPGA4 follows the omega-square model (red). The observed Fourier spectra were calculated from the second wave packet for which the contribution from SPGA4 is dominant. Both spectra combine the two horizontal components and are smoothed with a Parzen window with a band width of 0.05 $\mathrm{Hz}$.
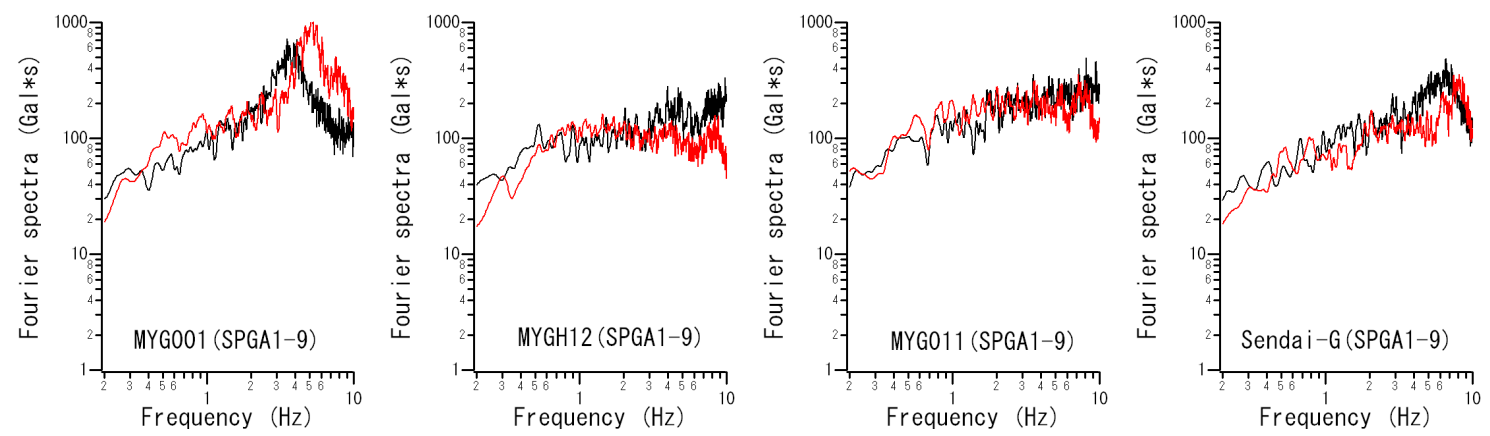

Fig. 16 The Fourier spectra of the observed waveforms during the 2011 Tohoku earthquake (black) and the synthetic Fourier spectra based on the source spectra of SPGA1-9 that are assumed to follow the omega-square model (red). The observed Fourier spectra were calculated from the entire record. Both spectra combine the two horizontal components and are smoothed with a Parzen window with a band width of $0.05 \mathrm{~Hz}$.
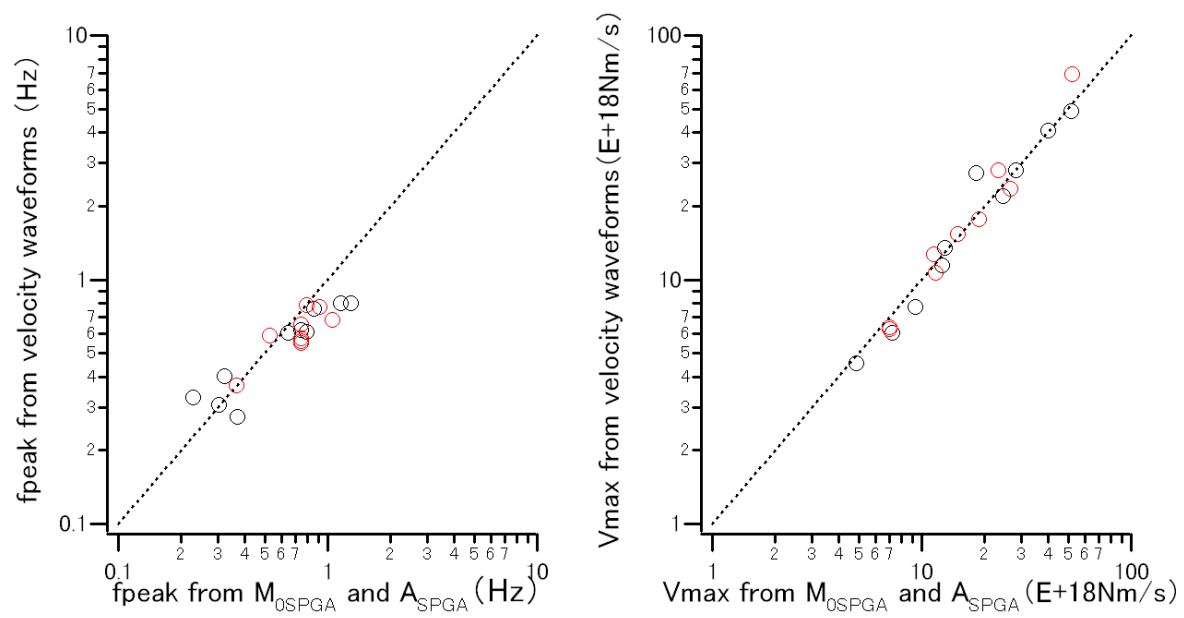

Fig. 17 Comparison of $f_{\text {peak }}$ and $V_{\max }$ obtained by interpolating the low -requency level $M_{0 \mathrm{SPGA}}$ and the high-frequency level $A_{\mathrm{SPGA}}$ in Table 1 using Eq. (1), with those obtained from the "velocity waveforms on the bedrock at a unit distance". The red circles represent the 2011 Tohoku earthquake and the black circles represent the other earthquakes.

proportional to the energy radiated from the SPGA in all directions; it is referred to as the "radiated energy" and denoted here as $E_{\mathrm{SPGA}}$. By performing the integration, it can be shown that 
$E_{\mathrm{SPGA}}=(1 / 8) \times M_{0 \mathrm{SPGA}}{ }^{0.5} \times A_{\mathrm{SPGA}}{ }^{1.5}$. There are only two independent parameters among the low frequency level, the high frequency level, and the radiated energy. Therefore, instead of discussing the scaling of the low-frequency level and the high-frequency level, we can discuss the scaling of, for example, the high-frequency level and the radiated energy. The values of radiated energy for the SPGAs are listed in Table 1.

\section{SCALING OF STRONG-MOTION PULSE GENERATION AREAS}

Based on the above discussion, we investigate how the low-frequency level $\left(M_{0 \mathrm{SPGA}}\right)$, the high-frequency level $\left(A_{\mathrm{SPGA}}\right)$ and the radiated energy $\left(E_{\mathrm{SPGA}}\right)$ of the SPGAs are related to the total size of the earthquakes.

\subsection{Characteristics of the source spectrum}

The displacement, velocity and acceleration source spectra for all the SPGAs in Table 1 are plotted in Fig. 18 (for the 1978 Miyagi-ken-oki earthquake, the SPGAs proposed by Nozu and Sugano ${ }^{14}$ is plotted). To enhance the comparison among different events, the largest source spectra for each event are plotted in Fig. 19. Here, the largest spectrum is defined as the spectrum which has the largest peak value for the velocity spectrum. In Figs. 18 and 19, the hatched regions correspond to the frequency range of $0.2-1 \mathrm{~Hz}$, which is the main focus of this article.

Figs. 18 and 19 show that the peaks of the velocity source spectra are in the frequency range of 0.2-1 $\mathrm{Hz}$ for all the SPGAs. This fact, however, is not surprising because the source model was originally developed to explain strong-motion pulses in this frequency range in the time domain.

A comparison among the different events reveals that the peak of the velocity source spectrum for the 2011 Tohoku earthquake appeared at higher frequencies than the peaks for the 1968 and 2003 Tokachi-oki earthquakes, even though the overall size of the 2011 Tohoku earthquake was larger. Moreover, at low frequencies $(0.2$ to $0.3 \mathrm{~Hz})$, the source spectrum for the 2011 Tohoku earthquake is smaller than those for the 1968 and 2003 Tokachi-oki earthquakes. This result is in agreement with studies that found that "during the 2011 Tohoku earthquake, high-frequency ground motions were

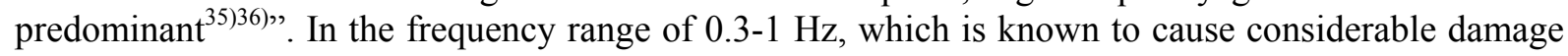
to quay walls, the source spectrum for the 2011 Tohoku earthquake was as significant as those for the 1968 and 2003 Tokachi-oki earthquakes.

\subsection{Scaling with respect to the entire size of the earthquake}

Next, we investigate how the low-frequency level, the high-frequency level, and the radiated energy of the SPGAs are related to the total size of the earthquake. The upper left panel of Fig. 20 shows the relation between the low-frequency level of the SPGAs and $M_{\mathrm{w}}$. The black circles indicate the low-frequency level of the individual SPGAs and the red circles indicate the sum of the low-frequency levels. The trend for the larger earthquakes with $M_{\mathrm{w}} \geqq 7.9$ is different from that of the smaller earthquakes. Thus, in the following discussion, we consider mainly the data from larger earthquakes with $M_{\mathrm{w}} \geqq 7.9$.

The upper right panel of Fig. 20 shows the relation between the high-frequency level of the SPGAs and $M_{\mathrm{w}}$. Again, the black circles indicate the high-frequency level of the individual SPGAs and the red circles indicate the sum of the high-frequency levels, where the summation is defined as the root of the sum of the squared high-frequency levels. We examined the relation between the sum of the high-frequency levels and the overall seismic moment $M_{0}$ to the power of $0,1 / 6,1 / 3,1 / 2,2 / 3,5 / 6$ and 1 for the earthquakes $\left(M_{\mathrm{w}} \geqq 7.9\right)$. The smallest residual was obtained for $M_{0}{ }^{1 / 3}$, with the regression line obtained as

$$
\log _{10}\left(\text { Sum of } A_{\mathrm{SPGA}}\right)=0.5 M_{\mathrm{w}}+16.31 \quad\left(M_{\mathrm{w}} \geqq 7.9\right)
$$

and plotted in the upper right panel of Fig. 20 as a red line. This relation is in agreement with those of 

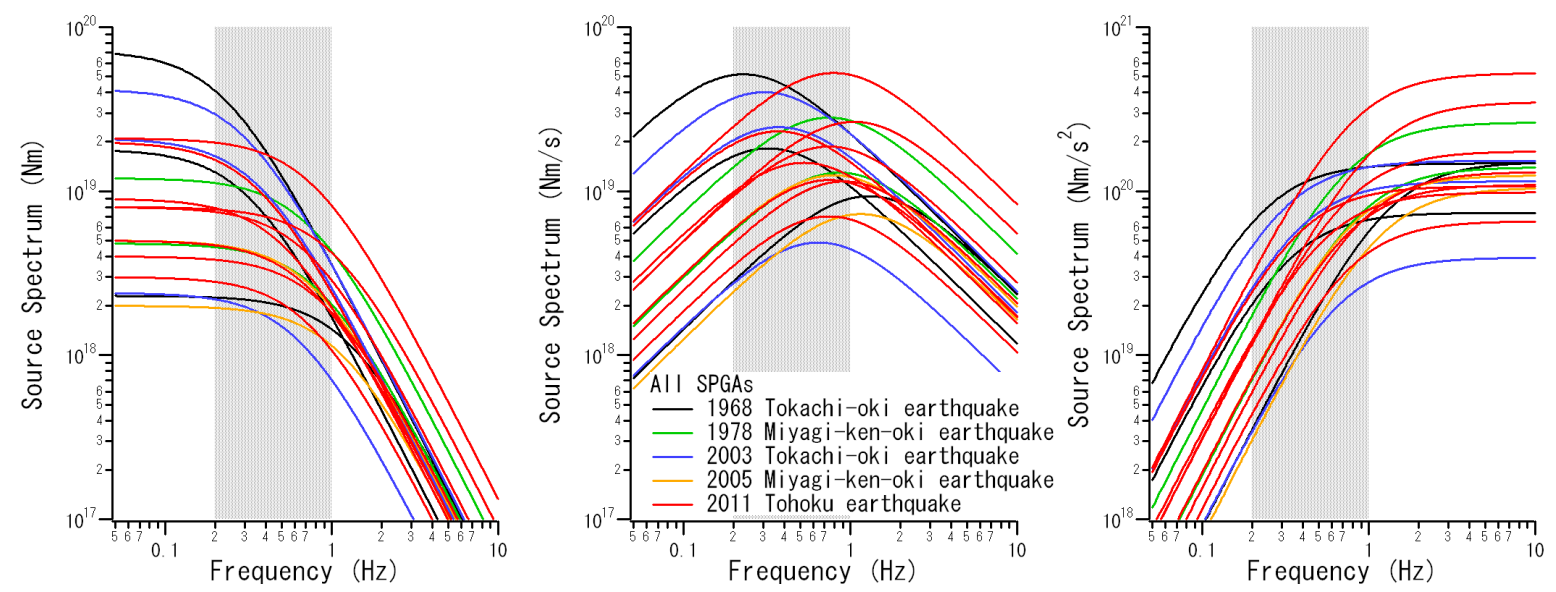

Fig. 18 Displacement (left), velocity (middle) and acceleration (right) source spectra for all the SPGAs
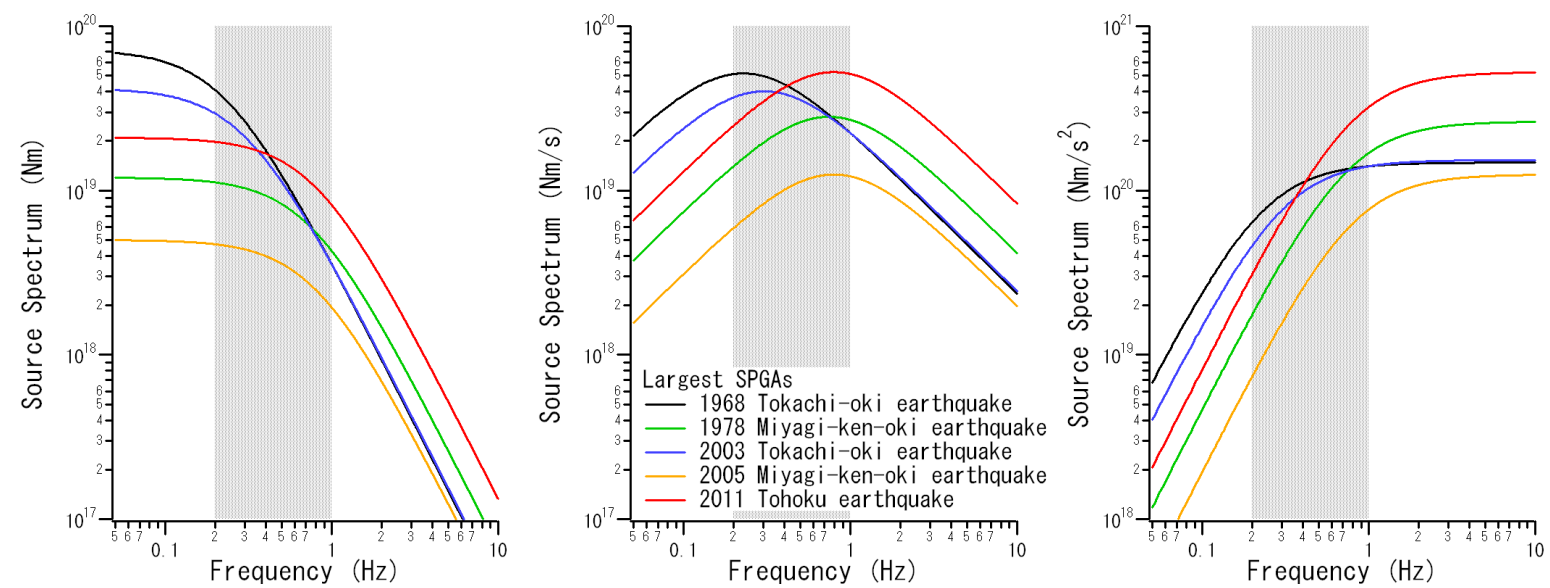

Fig. 19 Displacement (left), velocity (middle) and acceleration (right) source spectra for the largest SPGA in each event

Dan et al. ${ }^{37)}$ and $\mathrm{Satoh}^{38)}$ in the sense that the high frequency level is proportional to $M_{0}{ }^{1 / 3}$. On the other hand, the high-frequency level averaged within an event is related to the sum of the high-frequency levels via the number of SPGAs $N$ as

(Sum of $\left.A_{\mathrm{SPGA}}\right)=N^{1 / 2}$ (Average of $\left.A_{\mathrm{SPGA}}\right)$.

If the average of the high-frequency level is to be independent of the size of the earthquake, $N$ is required to be proportional to $M_{0}^{2 / 3}$. However, $N$ is proportional to $M_{0}^{1 / 3}$ for the larger earthquakes $\left(M_{\mathrm{w}} \geqq 7.9\right)$ as indicated by the red line in the lower right panel of Fig. 20. Furthermore, the high frequency-level of the individual SPGAs is proportional to $M_{0}{ }^{1 / 6}$ for the larger earthquakes $\left(M_{\mathrm{w}} \geqq 7.9\right)$ as indicated by the black line in the upper right panel of Fig. 20. The result suggests that, with the increase in seismic moment, the high-frequency level of the individual SPGAs increases. At the same time, the number of the SPGAs also increases and, as a result, the sum of the high-frequency levels increases in proportion to $M_{0}{ }^{1 / 3}$.

The lower left panel of Fig. 20 shows the relation between the radiated energy of the SPGAs and $M_{\mathrm{w}}$. Again, the black circles indicate the radiated energy of the individual SPGAs and the red circles indicate the sum of the radiated energy. The relation between the sum of the radiated energy and the overall seismic moment $M_{0}$ to the power of $0,1 / 6,1 / 3,1 / 2,2 / 3,5 / 6$ and 1 was investigated for the earthquakes with $M_{\mathrm{w}} \geqq 7.9$. The smallest residual was obtained for $M_{0}{ }^{1 / 2}$, with the regression line obtained as

$$
\log _{10}\left(\text { Sum of } E_{\mathrm{SPGA}}\right)=0.75 M_{\mathrm{w}}+33.34 \quad\left(M_{\mathrm{w}} \geqq 7.9\right)
$$

and plotted in the lower left panel of Fig. 20 as a red line. Thus, the sum of the radiated energy increases with the increasing total moment, but in a different way than the sum of the high-frequency 

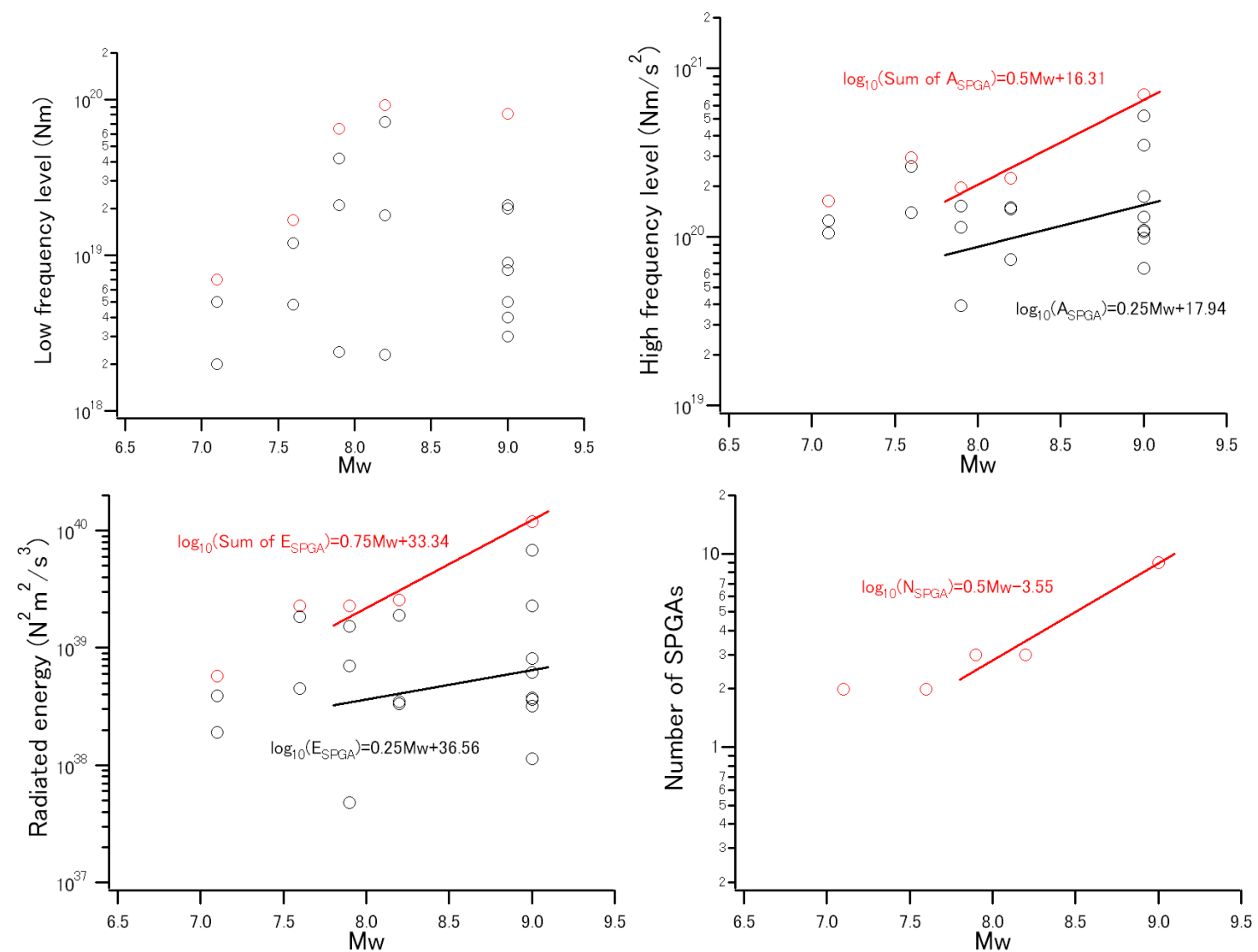

Fig. 20 The relation of the low-frequency level, high-frequency level, radiated energy, and the number of SPGAs to $\mathrm{M}_{\mathrm{w}}$

levels.

In the prediction problems, once the total moment is given, by using Eqs. (2) and (4), the sum of the high-frequency levels and that of the radiated energy of the SPGAs can be estimated for $M_{\mathrm{w}} \geqq 7.9$.

One distinctive character of the SPGAs of the 2011 Tohoku earthquake is that the peak of their velocity source spectra occurs at higher frequencies than the peaks for the 1968 and 2003 Tokachi-oki earthquakes, although the overall size of the 2011 Tohoku earthquake is larger (5.1). With the currently available data, we cannot judge whether this is typical of $M_{\mathrm{w}}=9.0$ earthquakes or it is unique to the Tohoku earthquake. If this is a unique characteristic of the Tohoku earthquake, then, as more data becomes available, the scaling of the SPGAs could become a different one than that shown in Fig. 20. The intention of this article is to satisfy the engineering need to develop a scaling which is at least in agreement with the data from the Tohoku earthquake, which is the only available data from an $M_{\mathrm{w}}=9.0$ earthquake.

Finally, the scaling obtained here implies that the effective stress of the SPGAs increases with increasing total moment for larger earthquakes $\left(M_{\mathrm{w}} \geqq 7.9\right)$. One possible interpretation of this relation is that, in a mega earthquake, the effective stress tends to be large because a mega earthquake corresponding to a super cycle ${ }^{39)}$ occurs under high stress accumulation at the plate boundary, although further study should be directed to the physical interpretation of this relation.

\section{SUMMARY AND SUBJECTS FOR FUTURE STUDY}

As mentioned in the introduction, strong ground motions in the frequency range of $0.2-1 \mathrm{~Hz}$ observed at many sites along the coast of Miyagi through Ibaraki Prefectures during the 2011 Tohoku earthquake are characterized by distinct pulses. These strong-motion pulses are similar to those 
resulting from shallow crustal earthquakes in a sense that they appear in a frequency range of engineering importance. Because strong-motion pulses from huge subduction earthquakes can also cause significant damage to structures, it is significantly important to consider the generation of such pulses in the strong motion prediction for huge subduction earthquakes, especially when the prediction is aimed at seismic design of structures. In this article, we first presented examples of strong-motion pulses from huge subduction earthquakes. Then, we compiled source models to reproduce those pulses. Finally, we investigated the characteristics of SPGAs, focusing on the relationships between the SPGA parameters and the earthquake size. The main conclusions can be summarized as follows.

1. Strong-motion pulses were generated by the 2011 Tohoku earthquake as well as by many other huge subduction earthquakes (and smaller subduction earthquakes) which left strong-motion data including the 2003 Tokachi-oki earthquake and the 1978 Miyagi-ken-oki earthquake. It is clear that the strong-motion pulses originated from the causative fault. The pulses are similar to those generated by shallow crustal earthquakes in terms of their shape and period.

2. Conventional source models designed to reproduce strong-motion pulses generated by huge subduction earthquakes were compiled. We propose the term "Strong-motion Pulse Generation Areas (SPGAs)" for the subevens that generated the strong-motion pulses (named "super asperities" in previous studies), because the definition of the term "asperity" itself is currently in a transition period. One notable characteristic of the SPGA is that it occupies a significantly smaller region than the conventional SMGA.

3. Based on the above source models, the "velocity waveforms on the bedrock at a unit distance" were calculated (equivalent to waveforms obtained by removing the path and site effects from the observed waveforms) and their amplitude and time width were investigated. These waveforms can be specified by the peak frequency and the peak value of the velocity source spectrum. Moreover, because the source spectrum of an SPGA can be approximated by the omega-square model, it is suffice to consider two parameters that define the omega-square model.

4. The relation of the high-frequency level and the radiated energy of the SPGAs to the total size of the earthquake $M_{0}$ was investigated. The sum of the high-frequency levels increases in proportion to $M_{0}^{1 / 3}$ whereas the sum of the radiated energy increases in proportion to $M_{0}{ }^{1 / 2}$.

Future studies should be conducted to reveal under what conditions SPGAs should be jointly used with SMGAs, to determine SPGA parameters when they are jointly used with SMGAs, and to distribute SPGAs on the causative fault in a prediction problems.

\section{ACKNOWLEDGMENT}

The strong-motion records were provided by the National Research Institute for Earth Science and Disaster Prevention of Japan, the National Institute for Land and Infrastructure Management of Japan, Japan Railways (JR), and the California Geological Survey. The strong-motion records of JR were provided on a floppy disk (Serial Number: R-087) ${ }^{40)}$.

\section{REFERENCES}

1) Kinoshita, S.: Kyoshin Net (K-net), Seim. Res. Lett., Vol. 69, 1998, pp.309-332.

2) Aoi, S., Obara, K., Hori, S., Kasahara, K. and Okada, Y.: New strong-motion observation network: KiK-net, Eos Trans. Am. Geophys. Union, Vol.81, 2000, p.329.

3) Nozu, A., Iai, S., Ichii, K. and Numata, A.: Frequency components of seismic ground motion which contribute to deformation of caisson quay walls, Symposium on Seismic Design of Geotechnical Works for L2 Ground Motions, The Japanese Geotechnical Society, 2000, pp.311-318 (in Japanese).

4) Sakai, Y., Koketsu, K. and Kanno, T.: Proposal of the destructive power index of strong ground motion for prediction of building damage ratio, J. Struct. Constr. Eng., AIJ, 
No.555, 2002, pp.85-91 (in Japanese with English abstract).

5) Nozu, A.: Prediction of strong ground motions from huge subduction earthquakes in the period range from 1 - 5 seconds, SSJ Fall Meeting, 2010, B12-04 (in Japanese).

6) Kurahashi, S. and Irikura, K.: Source model for generating strong ground motions during the 2011 off the Pacific coast of Tohoku Earthquake, Earth Planets Space, Vol.63, 2011, pp.571-576.

7) Irikura, K.: Near-fault ground motions causing the Great Hanshin Earthquake Disaster, Annuals, Disas. Prev. Res. Inst., Kyoto Univ., No.39A, 1996, pp.17-33 (in Japanese with English abstract).

8) Kamae, K. and Irikura, K.: Source model of the 1995 Hyogo-ken Nanbu earthquake and simulation of near-source ground motion, Bull. Seism. Soc. Am., Vol.88, 1998, pp.400-412.

9) Wald, D.J., Heaton, T.H. and Hudnut, K.W.: The slip history of the 1994 Northridge, California, earthquake determined from strong-motion, teleseismic, GPS, and leveling data, Bull. Seism. Soc. Am., Vol.86, 1996, pp.S49-S70.

10) Iwasaki, T., Wakabayashi, S., Kawashima, K. and Takagi, Y.: Strong-motion acceleration records from public works in Japan, Technical Note of PWRI, No.33, 1978 (in Japanese).

11) Nozu, A. and Wakai, A.: Annual report on strong motion earthquake records in Japanese ports (2010), Technical Note of the Port and Airport Research Institute, No.1243, 2011 (in Japanese with English abstract).

12) Nozu, A.: A super asperity model for the 2011 off the Pacific coast of Tohoku earthquake, Journal of Japan Association for Earthquake Engineering, Vol.12, 2012, pp.21-40 (in Japanese with English abstract).

13) Nozu, A., Nagao, T. and Yamada, M.: Site amplification factor for strong-motion sites in Japan based on spectral inversion technique and their use for strong-motion evaluation, Journal of Japan Association for Earthquake Engineering, Vol.7, 2007, pp.215-234 (in Japanese with English abstract).

14) Nozu, A. and Sugano, T.: Simulation of strong ground motions from shallow crustal and subduction-zone earthquake based on site-specific amplification and phase characteristics, Technical Note of the Port and Airport Research Institute, No.1120, 2006 (in Japanese with English abstract).

15) Matsushima, S. and Kawase, H.: Source model of a subduction zone earthquake with super-asperity, Chikyu Monthly, S55, 2006, pp.98-102 (in Japanese).

16) Satoh, T. and Kawase, H.: Estimation of characteristic source model of the 2005 west off Fukuoka prefecture earthquake based on empirical Green's function method, Proceedings of the 12th Japan Earthquake Engineering Symposium, pp.170-173 (in Japanese with English abstract).

17) Kawase, H., Satoh, T., Ho, N. and Umeda, N.: The 2005 west off Fukuoka earthquake: strong motions, their damage potentials, and inverted rupture process, Proceedings of the 12th Japan Earthquake Engineering Symposium, pp.162-165 (in Japanese with English abstract).

18) Ikeda, T., Kamae, K. and Irikura, K.: Source modeling using the empirical Green's function method and strong ground motion estimation considering nonlinear site effect, J. Struct. Constr. Eng., AIJ, No.665, 2011, pp.1253-1261 (in Japanese with English abstract).

19) Nozu, A.: Modeling semi-short-period ground motions from crustal earthquakes using characterized source models, Report of the Port and Airport Research Institute, Vol.50, 2011, pp.133-195 (in Japanese with English abstract).

20) Miyake, H., Iwata, T. and Irikura, K. : Source characterization for broadband 
ground-motion simulation: kinematic heterogeneous source model and strong motion generation area, Bull. Seism. Soc. Am., Vol.93, 2003, pp.2531-2545.

21) Asano, K. and Iwata, T.: Strong ground motion generation during the 2011 off the Pacific coast of Tohoku earthquake revealed by the broadband strong motion simulation, SSJ Fall Meeting, 2011, A11-06 (in Japanese).

22) Satoh, T.: Source model of the 2011 off the Pacific coast of Tohoku earthquake using empirical Green's function method and scaling law of the source parameters, SSJ Fall Meeting, 2011, B22-04 (in Japanese).

23) Kawabe, H., Kamae, K. and Uebayashi, H.: Source model of the 2011 Tohoku-chiho Taiheiyo-oki earthquake, SSJ Fall Meeting, 2011, B22-05 (in Japanese).

24) Irikura, K. and Kurahashi, S. : Strong ground motions during the 2011 Pacific coast of Tohoku, Japan, earthquake, http://www.kojiro-irikura.jp/pdf/ One-year-after-the-2011Tohoku_irikura_revised.pdf, 2012.

25) Satoh, T.: Source modeling of the 2011 off the Pacific coast of Tohoku earthquake using empirical Green's function method - from the viewpoint of the short period spectral level of interplate earthquakes -, J. Struct. Constr. Eng., AIJ, No.675, 2011, pp.695-704 (in Japanese with English abstract).

26) Engineering Seismology Group, Port and Airport Research Institute: A characterized source model for the August 16, 2005, Miyagi-ken-oki earthquake (M7.2), http://www.pari.go.jp/bsh/jbn-kzo/jbn-bsi/taisin/sourcemodel/somodel_2005miyagiken oki.html, 2010.

27) Kowada, A., Tai, M., Iwasaki, Y. and Irikura, K.: Evaluation of horizontal and vertical strong ground motions using empirical site-specific amplification and phase characteristics, J. Struct. Constr. Eng., AIJ, No.514, 1998, pp.97-104 (in Japanese with English abstract).

28) Nozu, A. and Sugano, T.: Simulation of strong ground motions based on site-specific amplification and phase characteristics - accounting for causality and multiple nonlinear effects -, Technical Note of the Port and Airport Research Institute, No.1173, 2008 (in Japanese with English abstract).

29) Nozu, A., Nagao, T. and Yamada, M.: Simulation of strong ground motions using empirical site amplification and phase characteristics - modification to incorporate causality -, Journal of JSCE, Ser. A, Vol. 65, 2009, pp.808-813 (in Japanese with English abstract).

30) Aki, K.: Scaling law of seismic spectrum, J. Geophys. Res., Vol.72, 1967, pp.1217-1231.

31) Irikura, K., Kagawa, T. and Sekiguchi, H.: Revision of the empirical Green's function method by Irikura(1986), SSJ Fall Meeting, 1997, B25 (in Japanese).

32) Nozu, A. and Irikura, K.: Strong-motion generation areas of a great subduction-zone earthquake: waveform inversion with empirical Green's functions for the 2003 Tokachi-oki earthquake, Bull. Seism. Soc. Am., Vol.98, 2008, pp.180-197.

33) Kamae, K. and Kawabe, H.: Source model composed of asperities for the 2003 Tokachi-oki, Japan, earthquake $\left(\mathrm{M}_{\mathrm{JMA}}=8.0\right)$ estimated by the empirical Green's function method, Earth Planets Space, Vol.56, 2004, pp.323-327.

34) Yokoi, T. and Irikura, K.: Empirical Green's function technique based on the scaling law of source spectra, Zisin, the second series, Vol.44, 1991, pp.109-122 (in Japanese with English abstract).

35) Ohno, S.: Strong motion observation records during the 2011 Tohoku earthquake, Proceedings of the 31th Symposium on Earthquake Ground Motion, AIJ, 2011, pp.13-20 (in Japanese with English abstract).

36) Sakai, Y. and Kanda, K.: Strong ground motion and damage to houses and buildings in the 2011 Tohoku-chiho Taiheiyo-oki earthquake, Proceedings of the 31th 
Symposium on Earthquake Ground Motion, AIJ, 2011, pp.51-56 (in Japanese with English abstract).

37) Dan, K., Watanabe, M., Sato, T. and Ishii, T.: Short-period source spectra inferred from variable-slip rupture models and modeling of earthquake faults for strong motion prediction by semi-empirical method, J. Struct. Constr. Eng., AIJ, No.545, 2001, pp.51-62 (in Japanese with English abstract).

38) Satoh, T.: Scaling law of short-period source spectra for crustal earthquakes in Japan considering style of faulting of dip-slip and strike-slip, J. Struct. Constr. Eng., AIJ, No.651, 2010, pp.923-932 (in Japanese with English abstract).

39) Satake, K.: Fault models of the 2011 off the Pacific coast of Tohoku earthquake and supercycle of giant earthquakes, Kagaku, Iwanami, Vol.81, 2011, pp.1014-1019.

40) Nakamura, Y., Uehan, F. and Inoue, H.: Waveform and its analysis of the 1995 Hyogo-Ken-Nanbu earthquake, Earthquake Information, Railway Technical Research Institute, No.23d, 1995 (in Japanese).

(Original Japanese Paper Published: September, 2012)

(English Version Submitted: October 20, 2014)

(English Version Accepted: November 21, 2014) 